\title{
Polymerically Modified Layered Silicates: An Effective Route to Nanocomposites
}

\author{
Jinguo Zhang ${ }^{1, *}$, E. Manias ${ }^{1,2}$, and Charles A. Wilkie ${ }^{3}$ \\ ${ }^{1}$ Department of Materials Science and Engineering, Pennsylvania State University, University Park, PA 16802, USA \\ ${ }^{2}$ Department of Materials Science and Technology, University of Crete, Herakleion, Greece \\ ${ }^{3}$ Department of Chemistry, Marquette University, Milwaukee, WI 53201, USA
}

\begin{abstract}
Polymer/clay nanocomposites have been under an extensive investigation for about 15 years. Traditional methods to modify the clay are usually limited to small organic cations, preferably containing long alkyl chain(s), which are exchanged with the inorganic cations in the clay gallery. This article provides a comprehensive review on the strategies for clay modification using polymeric surfactants or polycations: from the synthesis of such surfactants, through the preparation of the polymerically modified clays, and to the fabrication of the respective polymer nanocomposites and their properties.
\end{abstract}

\section{CONTENTS}

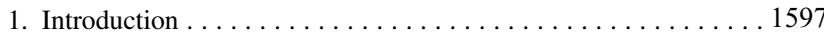

2. Synthetic Strategies for Polymeric Surfactants........... 1599

2.1. One End Functionalized Polymeric Surfactant . . . . . . . . 1599

2.2. $\alpha, \omega$ Functionaled Polymeric Surfactant . . . . . . . . . 1600

2.3. Polymeric Surfactants Containing

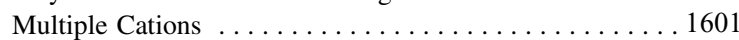

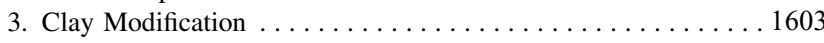

4. Characterization of Polymerically Modified Clays . . . . . . . . 1603

4.1. Thermogravimetric Analysis (TGA) . . . . . . . . . . . 1603

4.2. Morphology of Polymerically Modified Clay . ......... 1604

5. Preparation and Morphology of Polymer Clay Nanocomposites 1607

6. Nanocomposite Properties . . . . . . . . . . . . . . . . 1610

6.1. Mechanical Properties .................. 1610

6.2. Thermal Stabilities . . . . . . . . . . . . . . . . . . 1610

6.3. Fire Properties . . . . . . . . . . . . . . . . . 1611

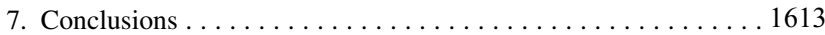

References and Notes ... . . . . . . . . . . . . . . . . . . . . 1614

\section{INTRODUCTION}

Well-defined polymer/clay composites are first reported by Blumstein in the 1960 's, ${ }^{1}$ who polymerized methyl methacrylate in the presence of a clay and found that the resulting polymer had unusual properties. At the time it was not known that these were nanocomposites and, indeed, the term did not yet exist. In the early 1990's, researchers at Toyota prepared a polyamide- 6 material by polymerization of caprolactam in the presence of a montmorillonite clay and found a remarkable enhancement in several properties. ${ }^{2}$ This work was the genesis of the vivid

\footnotetext{
*Author to whom correspondence should be addressed.
}

research which now occurs throughout the world on polymer nanocomposites and it has sparked several reviews and books on this subject. ${ }^{3-9}$ Pristine clays are hydrophilic while most polymers are hydrophobic and thus, except a few hydrophilic polymers, ${ }^{10-13}$ most polymers are not compatible (miscible) with pristine clays. To form polymer clay nanocomposites, the immiscibility between the polymer and the hydrophilic clay must be overcome by either modifying the polymer or, more frequently and easier, by modifying the clay. There are four different methods to render organophilic properties to the clay:

(1) ion exchange with organic cations (typically cationic surfactants);

(2) covalent bond formation through a grafting reaction;

(3) direct adsorption of molecules; and

(4) a combination of two of the methods listed above. 9

In-situ polymerization and melt intercalation are the most common methods to fabricate polymer/clay nanocomposites. The direct intercalation behavior of a molten polymer into an organically modified clay was first observed by Vaia et al. employing polystyrene and an alkyl-ammonium modified montmorillonite. ${ }^{14}$ Melt blending, which is "greener" than polymerization since it does not involve organic solvents, has become the preferred method to prepare polymer clay nanocomposites-also due to its lower barrier incorporation in industrial processing. As pointed out by Giannelis, ${ }^{4,15}$ the morpholoy of polymer/clay composites: phase separated (immiscible also known as a microcomposite), intercalated, and/or exfoliated (also known as delaminated) is determined by the nature of the polymer and clay functionalizations 
and their interactions and, in the presence of favorable interactions, nanocomposite formation can be achieved without the use of solvent. ${ }^{16,17}$ An exfoliated polyamide6/MMT nanocomposite, for example, can be easily fabricated by melt blending polyamide- 6 with an appropriate organically-modified clay, where the modifier contains only one long aliphatic chain. ${ }^{14,18,19}$ If polystyrene is used as the matrix, an intercalated nanocomposite can be obtained by melt blending only when the clay is modified by an onium salt containing two long aliphatic chains $;{ }^{20-22}$ whereas phase separated microcomposites are formed when a single aliphatic chain is used or a polar benzyl group is present. ${ }^{23}$ For non-polar polyolefins, such as polyethylene and polypropylene, immiscible structures are typically obtained by melt intercalation with common organically modified clays. ${ }^{24,25}$ Removing the edge hydroxyl groups can improve the nano-dispersion, ${ }^{26}$ and lead to the formation of an intercalated system; the same edge hydroxyls also offer possibilities for further modification of the clays by silane-surfactants, and it has been shown that semi-fluorinated silanes can effectively promote miscibility between $\mathrm{PP}$ and montmorillonite. ${ }^{27}$ In most cases, PE-g-MAH or PP-g-MAH is used as a compatibilizer $^{27-31}$ to promote polymer intercalation and nanocomposite formation for $\mathrm{PE}$ and $\mathrm{PP}$, respectively. This results in a two-step (masterbatch) process, where care should be taken on the extent of maleic anhydride (MAH) or maleic anhydrite functionalization of PE or PP: as has been pointed out before by Manias: ${ }^{27}$ too low MAH content does not promote nanocomposite formation, while too high MAH content leads to immiscibility between the neat (unfunctionalized) polymer and the masterbatch.

To avoid the MAH functionalized polymer, significant efforts have been focused on modifying pristine clays using PE or PP polymeric "surfactants" bearing ammonium or phosphonium cations. The usual surfactants used for ionic exchange with pristine clay contain one or two long alkyl chains, which contain between 12 and 18 methylenes and these generally have a molecular weight of about $500 \mathrm{~g} / \mathrm{mol}$. The molecular weights of polymeric/oligomeric (hereafter called polymeric) surfactants are based on the same aliphatic chemistry but are much longer and larger, around $5000 \mathrm{~g} / \mathrm{mol}$ and sometimes even above $10,000 \mathrm{~g} / \mathrm{mol}$. These high molecular weight "surfactants" are not soluble in water, which is the best solvent for
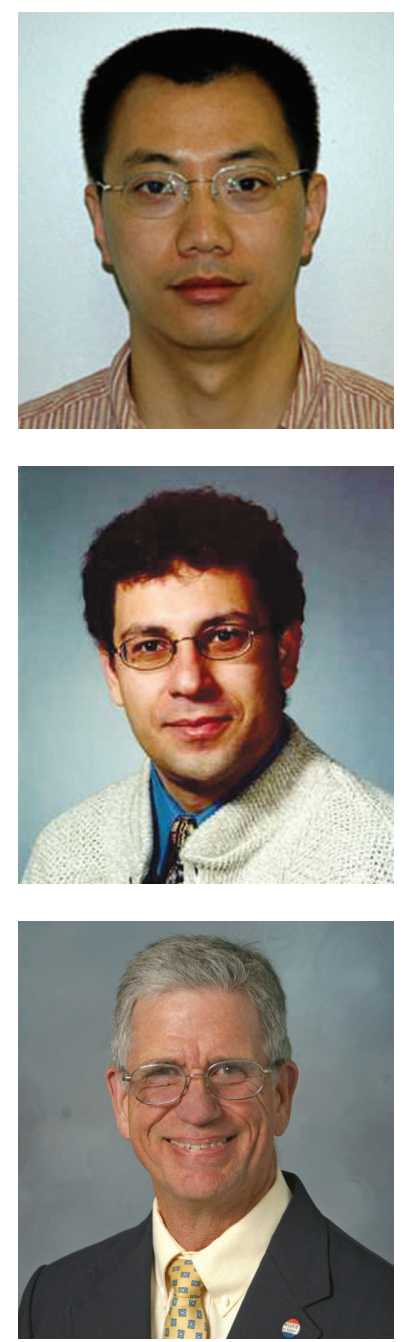

Charles A. Wilkie is the Pfletschinger-Habermann Professor of Chemistry at Marquette University. He received an undergraduate degree in chemistry from the University of Detroit and then a Ph.D. in inorganic chemistry from Wayne State University. He joined the faculty at Marquette University in 1967 as assistant professor and has risen through the ranks. His research interests have changed from the main group organometallic chemistry on which he first worked to fire retardancy and, more recently, to polymer nanocomposites. He has been a Fulbright-Hays scholar at the Universite Libre de Bruxelles. The work of the laboratory is involved with understanding how nanocomposite formation enhances fire retardancy, developing novel surfactants and investigating combinations of fire retardants and nanocomposite formation for enhanced fire retardancy. 
dispersing the pristine clay. A mixture of THF, or another organic solvent, and water is often used to disperse the clay in order to permit the cation exchange reaction. The cations to be inserted into the clay are usually quaternary ammonium cations, either formed on the backbone ${ }^{32}$ of the polymeric surfactants or pendant on the surfactant backbone, or can be a terminal functional group of the polymer. ${ }^{33}$ Independent of the location, the resulting polymerically modified clays (PCN-P) usually show a highly expanded gallery space and can be melt mixed with various homologous polymers to form nanocomposites with good nano-dispersion. ${ }^{34}$

This review focuses on the strategies to prepare different polymeric surfactants bearing cations, and on the respective clay modifications and polymer/clay nanocomposite formation through intercalation methods. Some properties of the polymer clay nanocomposites based on such polymerically modified clay will also be discussed.

\section{SYNTHETIC STRATEGIES FOR POLYMERIC SURFACTANTS}

Based on theoretical arguments, Balazs ${ }^{35}$ predicted that inorganic nanoparticle dispersion in polymer matrices could be realized by increasing the aliphatic chain length of the organic modifier. Despite the quantitative shortcomings of that theoretical approach (a higher fidelity theory ${ }^{36}$ is needed to capture the response of real experimental systems), it did put forward the qualitative energetic arguments invoked in the approach of the polymerically modified clays, and has-to some extent-paved the way for experimental studies in this direction. A few attempts have been made at grafting polymers onto the functional groups within clay. ${ }^{37-39}$ These approaches will not be included in this review since two steps are required to modify the clay. First, establish functional groups on the clay, and subsequently graft a polymer onto the clay through reaction with or initiation from these functional groups. Here, we will focus only on direct modification by polymeric surfactants.

\subsection{One End Functionalized Polymeric Surfactant}

An ammonium cation terminated polymeric surfactant was first reported by Hoffmann et al. ${ }^{40}$ Anionic polystyrene $(\mathrm{Mn}=5800 \mathrm{~g} / \mathrm{mol}$, DPI $=1.33)$ was capped by dimethylchlorosilane, then allyl amine was added to the silane to form an amine-terminated PS. Subsequently,<smiles>C=Cc1ccccc1</smiles><smiles>C=CCNC(C)CC(CC(CC(C)CC)c1ccccc1)CC(CC(CC(C)CC)c1ccccc1)c1ccccc1</smiles>

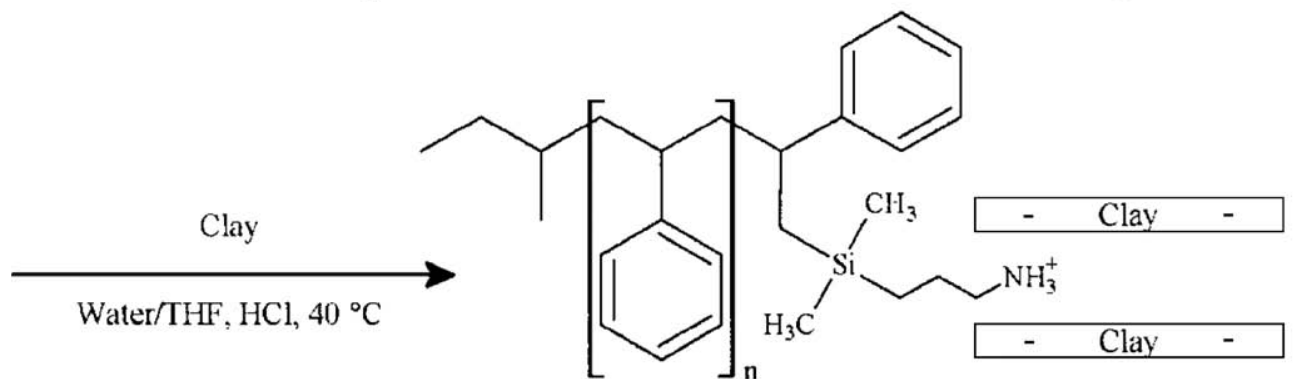

Fig. 1. Synthesis of ammonium-terminated PS and PS modified clay. Reprinted with permission from [40], B. Hoffmann et al., Macromol. Rapid Commun. 21, 57 (2000). () 2000, John Wiley \& Sons. 
a layered silicate, fluromica, was successfully modified with this amine-terminated polystyrene $\left(\mathrm{PS}-\mathrm{NH}_{3}^{+}\right)$. The process is depicted in Figure 1.

In a later approach, a series of model polymer layered silicate nanocomposites were fabricated and characterized to investigate the effect of surfactant length on nanocomposite morphology. ${ }^{41}$ Quaternary ammonium $\left[-\left(\mathrm{CH}_{3}\right)_{3} \mathrm{~N}^{+}\right]$end-functionalized PS surfactants with varied molecular weight (Mn 17600, 11200, 6800, 2700, and $1735 \mathrm{~g} / \mathrm{mol}, \mathrm{PDI} \approx 1.05$ ) were prepared using amine terminated PS followed by reaction with dimethyl sulfate. The molecular weights of these PS were well-controlled by living anionic polymerization. The end functional amine was introduced by reacting the living polymer-end with $\alpha$-halo- $\omega$-aminoalkane derivatives. ${ }^{41,42}$

A different, one-step, synthesis was used to make ammonium terminated polypropylene. Amine terminated PP (PP-t- $\left.\mathrm{NH}_{2} \mathrm{Mn}=58900 \mathrm{~g} / \mathrm{mol}, \mathrm{PDI}=2.30\right)$ was synthesized by addition of an appropriate transfer agent in a PP synthesis scheme employing rac- $\mathrm{Me}_{2} \mathrm{Si}[2-$ $\mathrm{Me}-4-\mathrm{Ph}(\mathrm{Ind})]_{2} \mathrm{ZrCl}_{2} / \mathrm{MAO}$ complex as a catalyst. ${ }^{43,44}$ Specifically, the metallocene-mediated polypropylene was functionalized by styrenic chain transfer agents, followed by reaction with $\mathrm{H}_{2}$ to complete the chain transfer reaction and add an amine as a terminal group. Ammonium terminated PP was then obtained by reaction with hydrochloric acid; the molecular weight of the functionalized PP can be controlled through the molar ratio of [chain transfer agent $] /[$ propylene]. For high molecular weight PP, the concentration of functional groups is very low, but they still exhibit high reactivity for clay modification: Exfoliated PP-t- $\mathrm{NH}_{3}^{+} / \mathrm{MMT}$ was prepared though static melt mixing ${ }^{33}$ of $90 \%$ ammonium terminated PP and 10\% MMT. The exfoliated structure can be maintained after further mixing by static melt blending of this $\mathrm{PP}-\mathrm{t}-\mathrm{NH}_{3}^{+} / \mathrm{MMT}$ with neat (unfunctionalized) PP. The synthetic scheme is shown in Figure 2.

\section{2. $\alpha, \omega$ Functionaled Polymeric Surfactant}

An $\alpha, \omega$ diamine-butadiene acrylonitrile coplolymer (ATBN), which contains $18 \%$ acrylonitrile, was used by Akelah $^{45,46}$ to modify MMT through cation exchange reactions. The molecular weight of ATBN determined by

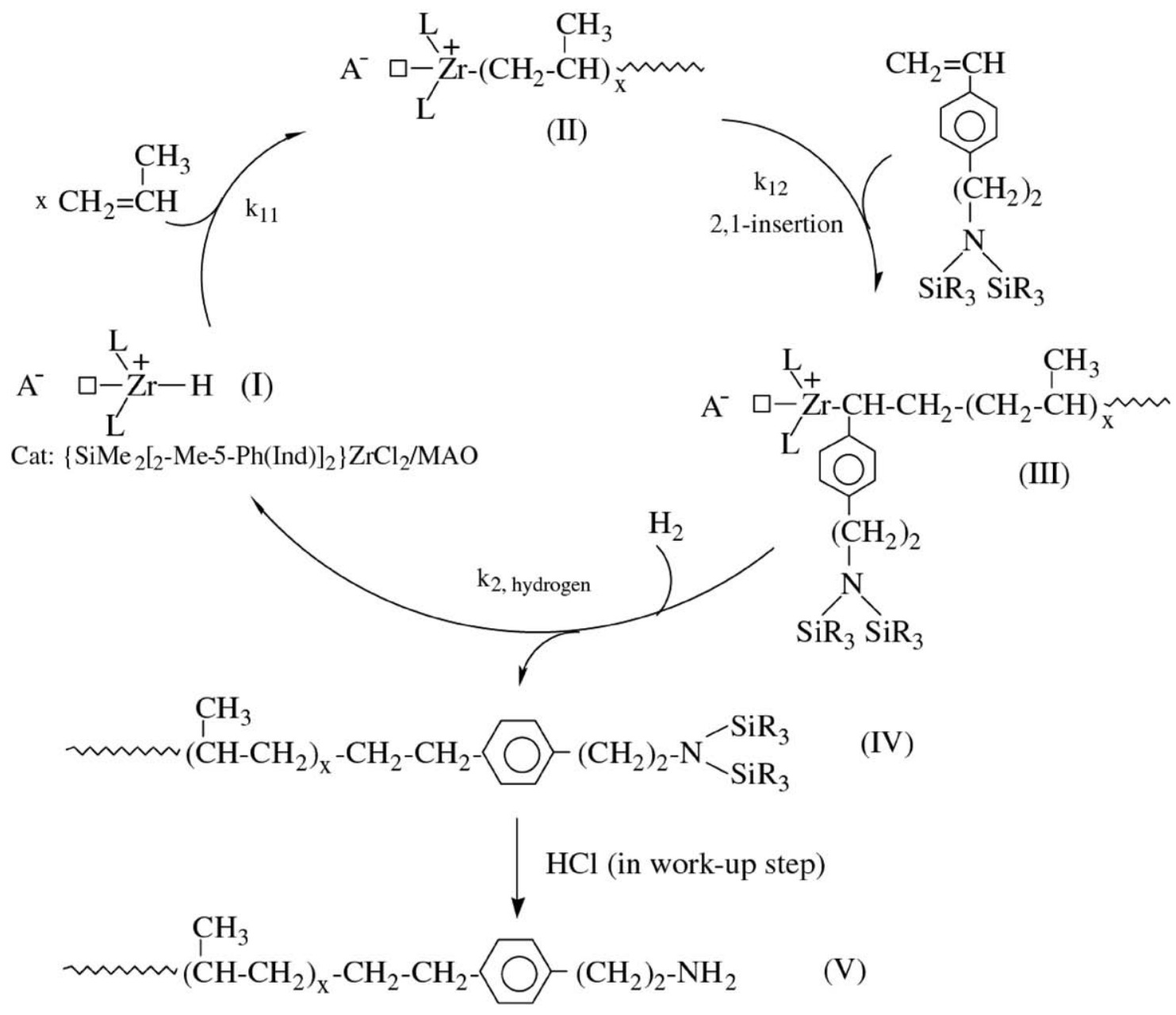

Fig. 2. Metallocene-mediated synthesis of amine terminated polypropylene. Reprinted with permission from [44], T. C. Chung, J. Organometal. Chem. 690, 6292 (2005). (C) 2005, Elsevier. 


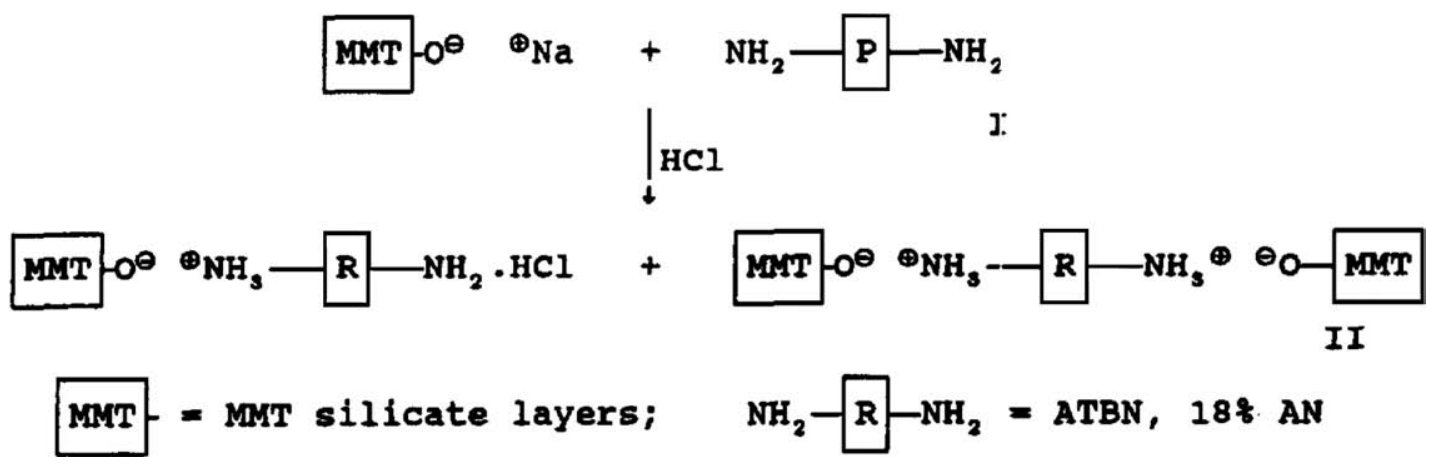

Fig. 3. Preparation of the rubber-MMT material. Reprinted with permission from [46], A. Akelah et al, Mater. Lett. 22, 97 (1995). () 1995, Elsevier.

GPC was found to be $1090 \mathrm{~g} / \mathrm{mol}$ with a polydispersity of 6.75. The general formula of ATBN is: $\mathrm{NH}_{2}-\left\{\mathrm{PBD}_{8.2}-\right.$ $\left.\mathrm{PAN}_{1.8}\right\}-\mathrm{NH}_{2}$. The modified clay was obtained after quaternizing the amines with concentrated $\mathrm{HCl}$; based on the quantities used, the final product is a mixture which contains 33\% diammonium terminated ATBN, 33\% with one amine and one ammonium terminated ATBN and 33\% free amine. The synthetic route is shown in Figure 3.

A different approach utilizing a difunctional $\alpha, \omega$ terminated polymer i.e., $\alpha, \omega$ diamine-butadiene acrylonitrile, ${ }^{47,48}$ was also used to make similar polymerically modified MMT. In this study, a liquid ATBN, which contained $17 \%$ acrynitrile and had a molecular weight of 3400 , was reacted with excess aqueous $\mathrm{HCl}$ to fully quaternize both amines. Significant differences exist in the behavior of these two systems, as will be presented later in this review.

\subsection{Polymeric Surfactants Containing Multiple Cations}

\subsubsection{Polymeric Cations on the Backbone}

A polymeric quaternary ammonium salt $(\mathrm{PQAS})^{32}$ was formed by the reaction between equimolar amounts of p-dichloroxylene and $N, N, N^{\prime}, N^{\prime}$-tetramethyl-1,6-hexanediamine. The resulting polymer is shown in Figure 4; its molecular weight was not reported.

\subsubsection{Polymeric Cations Pending onto the Backbone}

(a) Copolymer Based on Vinylbenzyl Chloride (VBC) A terpolymer ${ }^{49}$ was synthesized by free radical polymerization of styrene $(\mathrm{St}), \mathrm{VBC}$, and maleic anhydride (MAH)

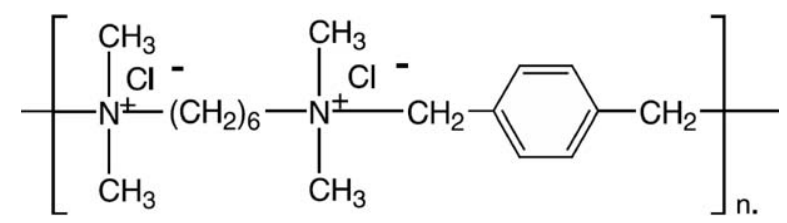

Fig. 4. Polymeric quaternary ammonium salts from the reaction between p-dichloroxylene and diamines. Reprinted with permission from [32], M. V. Burmistr et al., Polymer 46, 12226 (2005). ๑) 2005. at a molar ratio of 9.5:9.5:1. The resulting terpolymer was then quaternized with either tributylphosphine or triphenylphosphine; the reaction is shown in Figure 5.

To control the release rate of pesticides, the organic derivative of a selective herbicide, metribuzin (MB), was reacted with VBC, and other monomers, such as MMA, St or AA, at the desired feed ratios. ${ }^{50}$ The chloromethyl groups were reacted with triethylamine (TEA) to produce an ammonium salt, which was then intercalated into MMT. The swelling behavior in various solvents and the release of MB from the intercalated clays in various media and in soil (pots and field applications) were studied.

Significant work on polymeric surfactants has been done at Marquette University. ${ }^{51-61}$ These polymeric surfactants were mainly copolymers containing vinylbenzyl chloride, which was employed so that it could quaternize an amine or phosphine to form the onium salt. Figure 6 shows one example of this work-the synthesis of a copolymer of vinylbenzyl chloride and styrene and its subsequent conversion into an ammonium salt; the surfactant was termed as COPS. The starting monomers were polymerized through either bulk or solution polymerization and the molecular weight of these polymers (oligomers) was controlled to about $5000 \mathrm{~g} / \mathrm{mol}$. Depending on the ratio between the copolymerizing monomers,

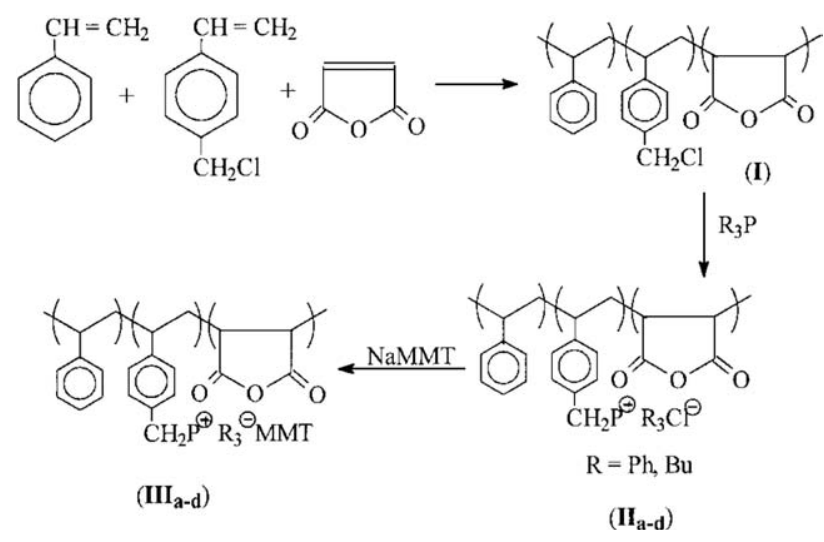

Fig. 5. Synthetic route of a terpolymer modified clay. Reprinted with permission from [49], N. Salahuddin and H. Akelah, Polym. Adv. Technol. 13, 339 (2002). @ 2002, John Wiley \& Sons. 


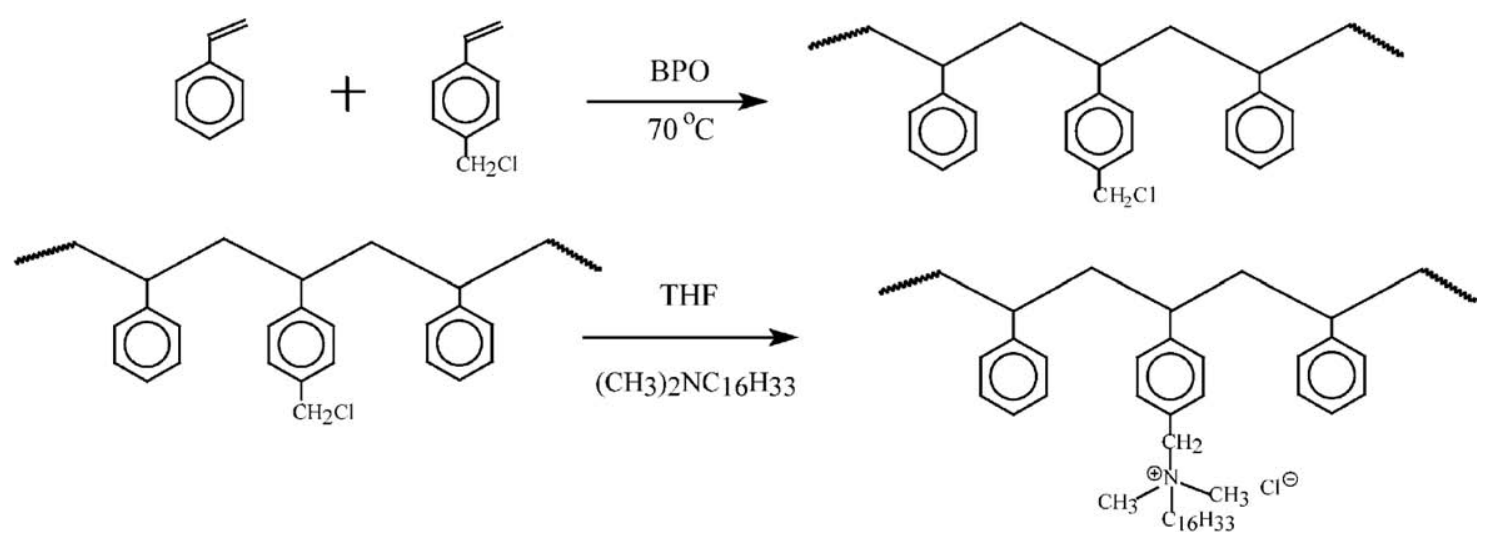

Fig. 6. Synthesis of the ammonium salt of COPS. Reprinted with permission from [51], S. Su et al., Polym. Degrad. Stab. 83, 333 (2004). @ 2004, Elsevier.

some units can contain more than one cation,,$^{51}$ and some may contain more than two cations. ${ }^{60,61}$ The polymeric surfactants based on the copolymerization of VBC with other monomers are summarized in Table I, where VBC is omitted.

(b) Copolymer Based on Vinyl Cations Subsequent work has been focused on simplifying the above synthetic

Table I. Summary of components for polymeric surfactants.

\begin{tabular}{lccc}
\hline \multicolumn{2}{c}{ Copolymerized monomers } & & \\
\cline { 1 - 2 } $\mathrm{M}_{1}$ & $\mathrm{M}_{2}$ & Amine or phosphine & Refs. \\
\cline { 1 - 2 } HEMA & - & TEA & {$[108]$} \\
St & - & TPP, DMHDA, & {$[51,52,53]$} \\
& - & TMA, IM, DMBA & \\
MMA & - & DMHDA & {$[47,48]$} \\
LA & - & TEA & {$[54]$} \\
NSt & - & TEA & {$[55]$} \\
St & MA & TBP, TPP & {$[49]$} \\
DAMB MMA, & St, AA, HEMA & TEA & {$[50]$} \\
DPVPP & St & DMHDA & {$[56]$} \\
St & LA & TEA & {$[57,58,59,60,61]$} \\
\hline
\end{tabular}

procedure. ${ }^{62-64}$ Monomers bearing ammonium cations were directly copolymerized with either MMA or St to produce polymeric surfactants. In one case, MHAB and MMA were bulk polymerized using BPO as the initiator. In another case, St, MA, and VBTACl were polymerized in a mixture of $\mathrm{CHCl}_{3} / 2$-butanone (1/1) due to the immiscibility between the two monomers. Their molecular weights were in the range of 3000 to 5000, as determined by intrinsic viscosity measurements. Figures 7 and 8 show the synthetic pathways for the two different ammoniums which contain vinyl moieties.

(c) Functionalized Polybutadiene Low molecular weight polybutadiene $(\mathrm{PBd})(\mathrm{Mn}=1000 \mathrm{~g} / \mathrm{mol})$ has also been functionalized for attachment to a clay ${ }^{65,66} \mathrm{VBC}$ was grafted onto the PBd backbone through free radial initiation. The byproduct, poly(vinylbenzyl chloride), was carefully washed away and then the grafted VBC was used to quaternize an amine, as shown in Figure 9.

Linear PBD $(\mathrm{Mw}=110,600 \mathrm{~g} / \mathrm{mol}, \mathrm{DPI}=1.03)$ from anionic polymerization ${ }^{67}$ was reinitiated by $\mathrm{s}$-BuLi to polymerize a small quantity of butadiene and a comblike structure was formed. The butadiene branches were<smiles>C=C(C)C(=O)OCC[N+](C)(CC)CCC(C)(C)CCC(C)(C)C(=O)OCC[N+](C)(CC)CC</smiles>

Fig. 7. Synthetic pathway for the MHAB cation. Reprinted with permission from [62], X. Zheng et al., Polym. Degrad. Stab. 91 , 289 (2006). (0 2006, Elsevier. 


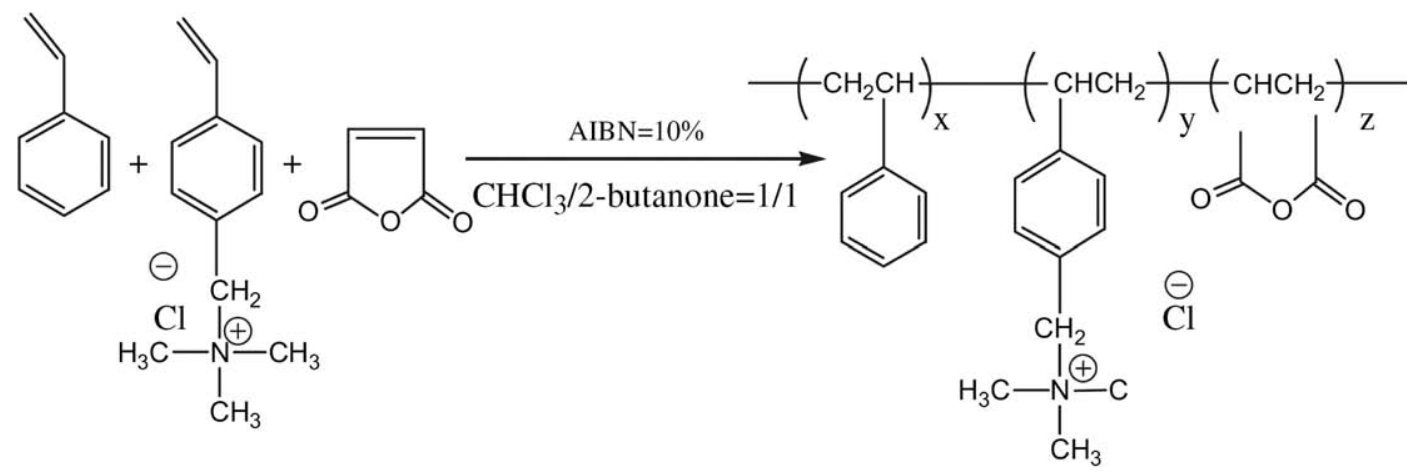

Fig. 8. Synthetic pathway for the VBTACl cation. Reprinted with permission from [64], X. Zheng et al., Polym. Degrad. Stab. 91, 108 (2006). (C) 2006, Elsevier.

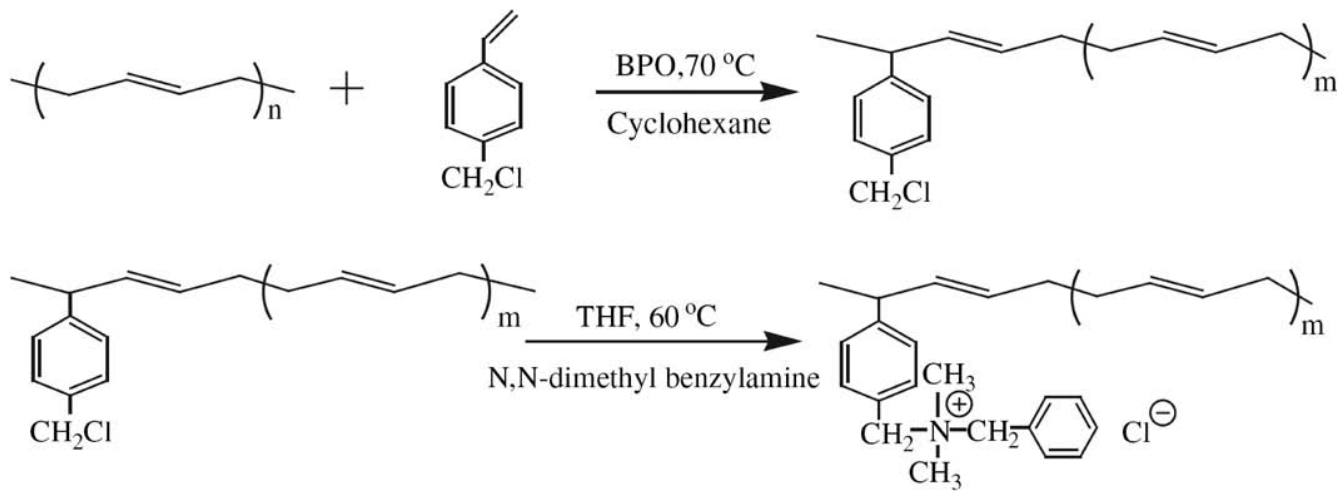

Fig. 9. The synthetic route for PBD surfactant. Reprinted with permission from [65], S. Su et al., Polym. Degrad. Stab. 84, 279 (2004). (C 2004, Elsevier.

terminated by dimethylaminopropyl chloride (DMAPCl). The comb PBD, which is functionalized with dimethylamine groups, was first hydrogenated, then quaternized using excess $\mathrm{HCl}$. The synthetic scheme is shown
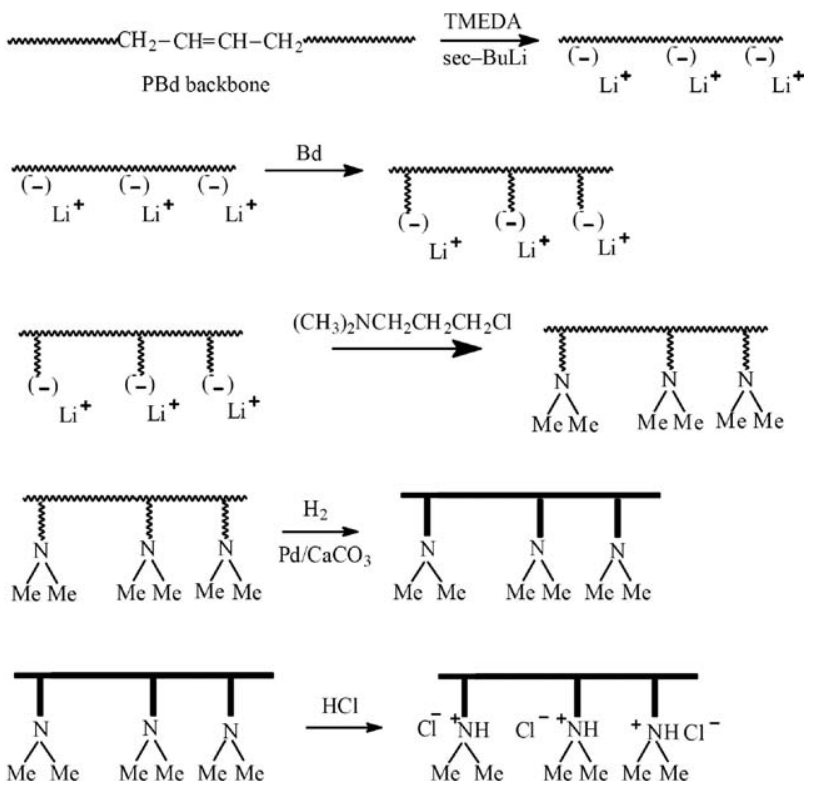

Fig. 10. Synthesis of combs with quaternized amine end-groups in each branch. Reprinted with permission from [67], K. Chrissopoulou et al., Polymer 46, 12440 (2005). ( 2005, Elsevier. in Figure 10; the number of branches grafted to the PBD backbone is not known.

\section{CLAY MODIFICATION}

Unlike the common alkyl ammonium cations used in clay modification, most of the polymeric cationic salts are not water soluble, so an organic solvent which will dissolve the polymeric surfactant is needed to facilitate the ion-exchange reaction. For example, when functionalized ATBN was used as the modifier, 1-4 dioxane or DMSO were selected to dissolve the polymeric surfactant while the clay is dispersed in a mixture of $\mathrm{H}_{2} \mathrm{O}$ and the selected solvent. For the polymeric surfactants listed in Table I, THF was frequently used. For end-functionalized PP with a relatively high molecular weight, and thus a small amount of terminal ammonium, and static intercalation ${ }^{33}$ in absence of a solvent, was employed to modify the pristine clay, completely eliminating the use of solvents.

\section{CHARACTERIZATION OF POLYMERICALLY MODIFIED CLAYS}

\subsection{Thermogravimetric Analysis (TGA)}

When characterizing PCN-P systems, there are two purposes for employing thermogravimetric analysis: (a) to 
determine the inorganic (clay) content of the polymerically modified clay, and (b) to obtain information on the thermal stability of the new material. When multiple cations per polymer chain exist, there is a statistically important probability that some of these cations are not bound to the clay; for a given clay, i.e., a given cation exchange capacity, the organic content will be quite different depending on the number of polymer-cations which are bound on the clay. The common clay organic modifications begin to degrade at about $150-200{ }^{\circ} \mathrm{C}$ by the Hofmann elimination ${ }^{68-70}$ depending on the experimental condition; many of these polymerically modified clays show extraordinarily better thermal stability, and degradation does not commence until about $300{ }^{\circ} \mathrm{C}$, or even higher, depending on the substituents.

In the ATBN modified MMT, ${ }^{46}$ the starting composition contained 33\% MMT and 67\% organic surfactant but the final product contains $40 \%$ inorganic and $60 \%$ organic, as shown in the TGA in Figure 11. Assuming that all of the MMT was modified, then more than $10 \%$ of the starting ATBN was lost. In another publication by the same group, more than $15 \%$ was reported lost. TGA provides a crucial evaluation of the modification quality and of the composition of the polymerically modified clay; the enhanced thermal stability of polymerically modified clay has been discussed in a recent review. ${ }^{71}$

The typical inorganic clay content in a polymerically modified clay is about $25 \%$, and this inorganic content can be well controlled by varying the amount of monomer containing the alkylating agent in the copolymer. Taking triclay, in which clay is modified by a terpolymer containing St, VBC and LA, as an example, the inorganic clay content can be controlled at $25 \%, 37.5 \%$, and $50 \%$ by altering the ratio of the three components during the polymerization stage. The TGA curves are shown in Figure 12.

\subsection{Morphology of Polymerically Modified Clay}

The most frequently used methods to determine the structure of polymer clay nanocomposites are X-ray diffraction

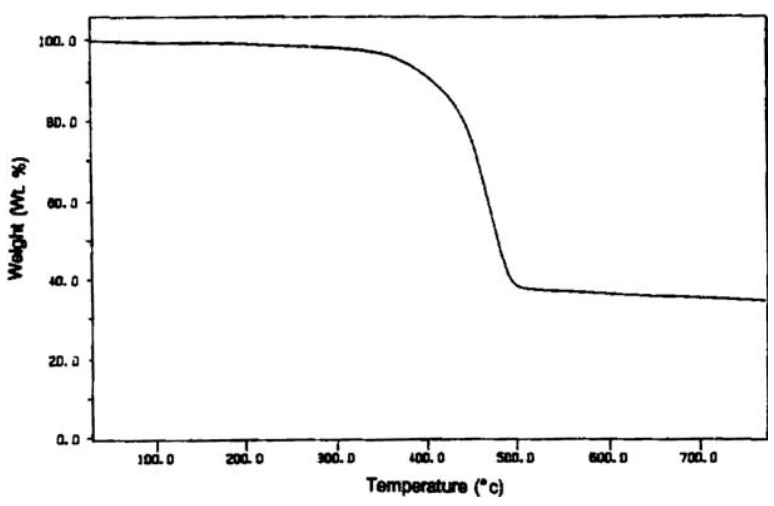

Fig. 11. TGA curve for the ATBN-MMT material. Reprinted with permission from [46], A. Akelah et al., Mater. Lett. 22, 97 (1995). () 1995, Elsevier.

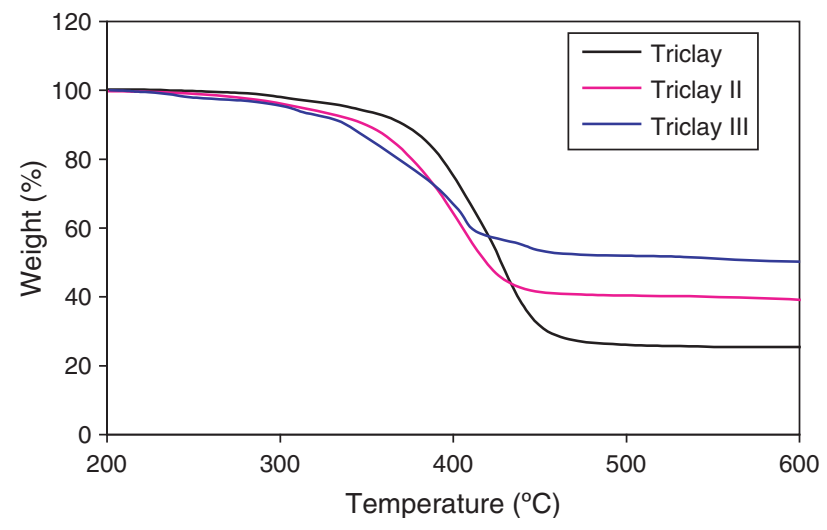

Fig. 12. TGA characterization of triclays containing different amount of inorganic clay. Adapted with permission from [58], J. Zhang et al., Polym. Degrad. Stab. 91, 641 (2006). (C) 2006, Elsevier; from [60], J. Zhang et al., Polym. Degrad. Stab. 91, 298 (2006). () 2006, Elsevier; and from [61], J. Zhang et al., Polym. Degrad. Stab. 91, 2665 (2006). (C) 2006, Elsevier.

(XRD) and transmission electron microscopy (TEM). $\mathrm{XRD}$ is based on the well-known Bragg's equation, and can quantify the periodicity of well-stacked clay in parallel registry; thus, XRD is very useful to determine the $d$-spacing of intercalated layered silicates. In general, dry inorganic layered silicates (smectides) show diffraction at about 8 degree $(2 \theta)$, which corresponds to a $d$-spacing of about $1 \mathrm{~nm}$. The thickness of diffracting clay stacks, $c f$. number of individual clay platelets per stack, can also be calculated from the breadth of the XRD peak, using the Scherrer equation. ${ }^{72}$

$\mathrm{X}$-ray diffraction alone is not enough to determine the morphology of a nanocomposite, in fact the use of XRD alone can be very misleading since both exfoliated and disordered structures will be XRD silent (show no peak). The usual complement to XRD is transmission electron microscopy (TEM) ${ }^{73}$ Both the low and high magnification micrographs should be presented. The low magnification micrograph emphasizes the overall clay dispersion, while the high magnification micrograph allows the observation of the individual clay layers, so that the morphology, intercalated or exfoliated, can be assigned. An intrinsic problem with TEM is that it can only observe a small portion of the sample, which may not be representative. A bulk measurement is definitely preferred, if one is to quantitatively establish the morphology of these systems. Some bulk measurements that have been used to complement TEM include, small and ultra-small angle X-ray scattering, SAXS and USAXS,${ }^{74}$ AFM, ${ }^{75}$ solid state NMR,${ }^{76}$ infrared spectroscopy, ${ }^{77}$ and rheological measurements. ${ }^{78}$

Weiss ${ }^{79}$ has made a comprehensive study of the intercalation behavior of $n$-alkylammonium ions into montmorillonite. As expected, the $d$-spacing of the organically modified silicate depends on the length of the alkyl chain and the charge (CEC) of the silicate layers. For rather high CEC values, the basal spacing can show step-wise increases for very moderate changes in the surfactant size, 

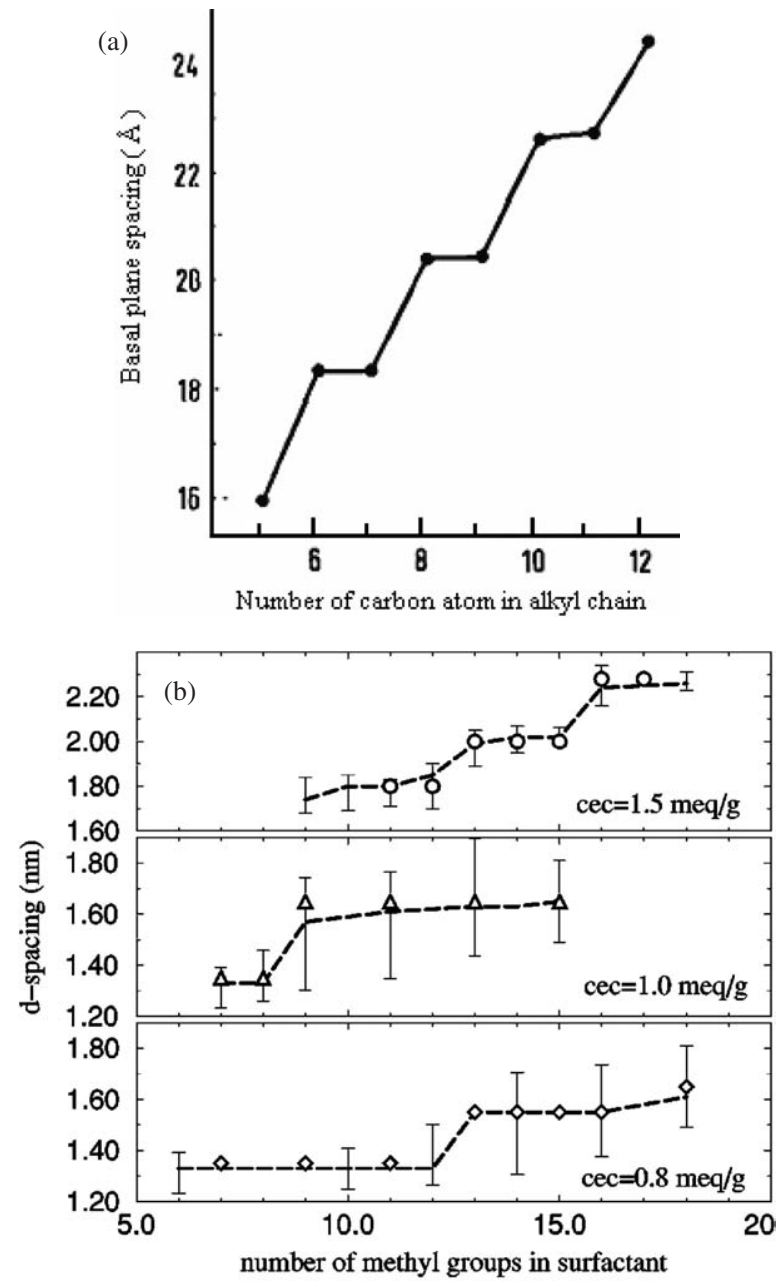

Fig. 13. (a) Increasing basal spacings on intercalation of $n$-alkylammonium ions with increasingly long alkyl chains. Reprinted with permission from [79], A. Weiss, Angew. Chem. Internat. Edit. 2, 134 (1963). (C) 1963, John Wiley \& Sons; (b) Experimental (dashed lines and vertical bars) and simulated (symbols) $d$-spacings for $n$-alkyl-ammonium modified 2:1 silicates. The dashed lines give the $d$-spacing at maximum $\mathrm{X}$-ray diffracted intensity and the bars depict the spread of the $d$-spacings measured in the XRD (peak width); bottom: SWy 2 montmorillonite and simulations for $\mathrm{CEC}=0.8 \mathrm{meq} / \mathrm{g}$, middle: AMS montmorillonite and simulations for $\mathrm{CEC}=1.0 \mathrm{meq} / \mathrm{g}$, upper: Dow-Corning fluorohectorite and simulations for $\mathrm{CEC}=1.5 \mathrm{meq} / \mathrm{g}$. Reprinted with permission from [80], E. Hackett et al., J. Chem. Phys. 108, 7410 (1998). (C) 1998, American Institute of Physics.

in Figure 13 for example it was observed that it was increased for every two methylenes added to the surfactant (see also Ref. [80], for a more detailed discussion).

The possible arrangement of the alkyl chains in the alkylammonium ions within the gallery space of the silicate can be inferred from the experimental works of Weiss, ${ }^{79}$ Lagaly, ${ }^{81}$ and Vaia, ${ }^{82}$ in which the alkyl chains were no longer than $\mathrm{C}_{20}$, or from computer modeling approaches [e.g., Ref. [80] and references therein] For most polymeric surfactants; the situation is much more complicated given the conformational permutations of the long polymeric chains attached on the inorganic layers.
In a first approximation these structures resemble those of hydrophilic polymer/clay nanocomposites, in which polymers can disperse clays that do not bear organicmodification surfactants: Specifically, (a) in the presence of strong specific interactions their structure would resemble "delaminated" structures where the fillers are separated by distances that reflect the organic loading of the hybrid ( $c f$. poly(vinyl alcohol)/ $/ \mathrm{Na}^{+}$montmorillonite structures; ${ }^{10,11}$ whereas (b) where the polymeric cations are the major favorable interaction between the polymeric surfactants and the clays, these structures would resemble more poly(ethylene oxide)/clay structures. ${ }^{12,13,83-88}$ Except for the end-functionalized polymeric surfactants, such as PS-t- $\mathrm{NH}_{3}^{+}$and PP-t- $\mathrm{NH}_{3}^{+}$, whose structure can be described via polymeric brush type of models, most other polymeric surfactants contain more than one cation per chain, which results in a more complicated arrangements on the surface of the silicate. Although the literature of polymeric adsorption-straightforward physisorption of homopolymers and/or of polymers containing "sticky" groups-is very extensive, ${ }^{89}$ little theoretical or modeling work has been performed on the intercalation behavior of polycations on clays. Williams-Daryn ${ }^{90}$ suggested three possible arrangements of gemini (divalent) surfactant chains in the silicate gallery, where high-CEC vermiculite in the form of quasi-single crystals was used; these arrangements are depicted in Figure 14. However, these kinds of surfactant configurations are highly idealized and definitely fall short of describing reality, for example all three proposed surfactant structures from Figure 14 are highly periodic and would give rise to surfactant XRD diffraction peaks, much like SAM structures on mica surfaces, but such XRD reflections are not observed experimentally.

In the case of polymerically modified clays, for example for ammonium-terminated PP modified MMT (90:10), XRD shows no $d_{001}$ peak, indicating that MMT exfoliates even under static melt intercalation in absence of any solvent or mechanical mixing, ${ }^{33}$ a well-dispersed structure was confirmed by TEM observations. ${ }^{33}$ Figure 15 compares the XRD patterns of these systems under two processing conditions: static melt intercalation at high temperature, which is effective and leads to intercalation of the end-functionalized PP and dispersed clay structures, and mixing at room temperature, which is not effective (the ca. $1.2 \mathrm{~nm} d_{001}$ of the hydrated $\mathrm{Na}^{+}$montmorillonite is clearly visible in the XRD). The terminal ammonium was suggested to anchor the PP chains (via ion exchange) onto the inorganic surfaces, and the hydrophobic PP "tail" exfoliates the clay platelets purely due to steric effects. Similarly, the use of an ammonium-terminated PS may have also brought about exfoliation of the silicate (fluoromica) as no peak was observed from the XRD pattern when the inorganic clay loading was $20 \% ;^{40}$ the XRD trace is shown in Figure 16. 

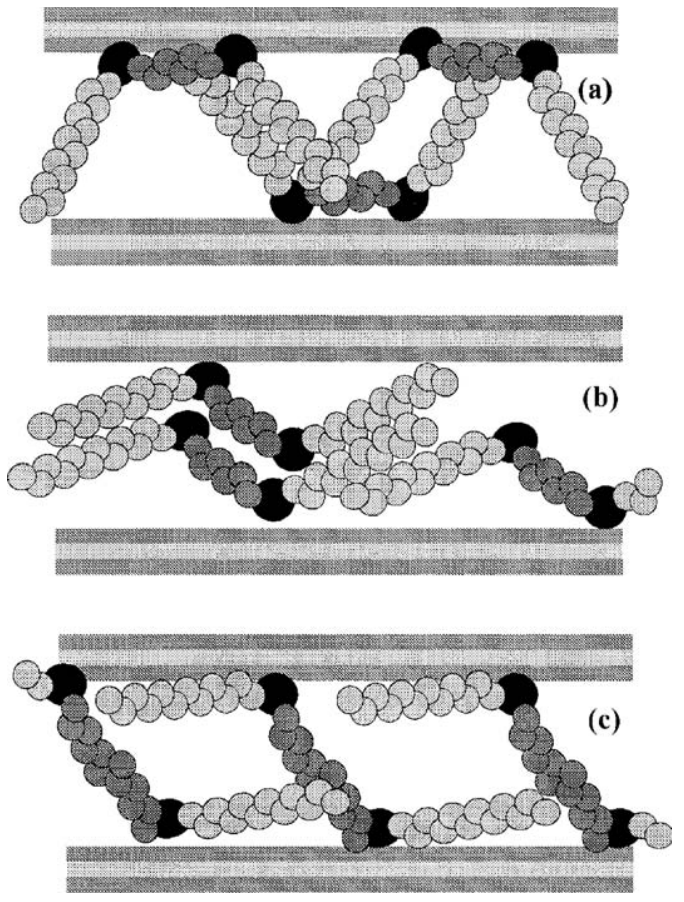
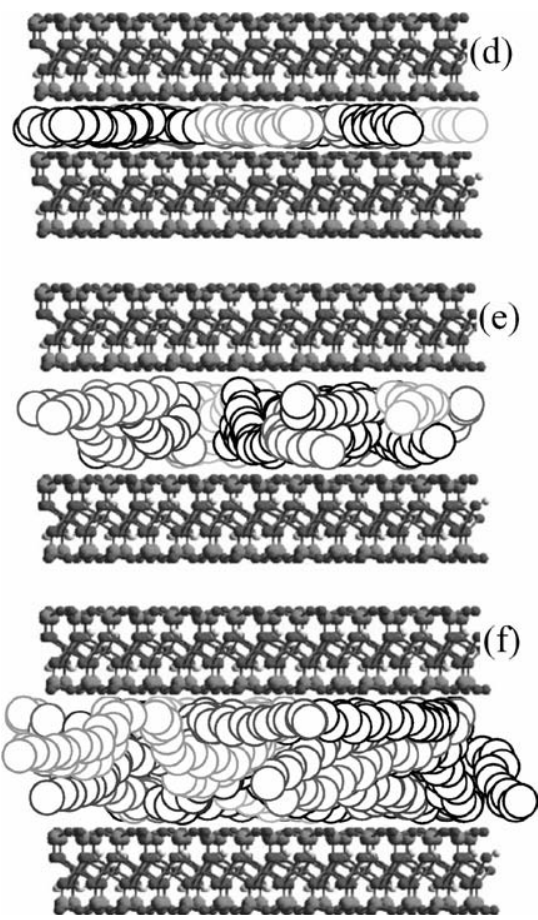

Fig. 14. (a)-(c) Idealized arrangements of gemini surfactant chains in the interlamellar space of high CEC vermiculite: (a) the spacer is lying flat on the surface to optimize the contact between the two head groups and the surface; (b) one head group is left "floating" in the interlamellar space; (c) the spacer is long enough to bridge the platelets. Reprinted with permission from [90], S. Williams-Daryn and R. K. Thomas, J. Colloid Interface Sci. 255, 303 (2002). (C) 2002, Elsevier. (d)-(f) More realistic surfactant configurations of monovalent cations bearing an alkyl chain, depending on surfactant length and clay CEC monolayers, bilayers and trilayers of monomers can be formed: $(\mathrm{d}) \mathrm{C}_{9} \mathrm{H}_{19}$ in a layered silicate with CEC $=0.8$ meq/g (low CEC montmorillonite); (e) $\mathrm{C}_{11} \mathrm{H}_{23}$ in a CEC $=1.0 \mathrm{meq} / \mathrm{g}$ (typical montmorillonite); and (f) $\mathrm{C}_{19} \mathrm{H}_{39}$ in CEC $=1.5$ meq/g (low CEC vermiculite); snapshots (d)-(f) are based on molecular dynamics simulations presented in Ref. [80]; only the carbon groups are shown and the hydrogens are omitted for clarity.

On the other hand, the protonated $\alpha, \omega$-diamine butadiene acrylonitrile (ATBN), modified clay shows a relatively small expansion of the clay gallery space; the $d$-spacing of the polymerically-modified clay increases by $6 \AA$ from $9.3 \AA$ in the pristine clay to $15.2 \AA{ }^{46}$ Pressure-molded

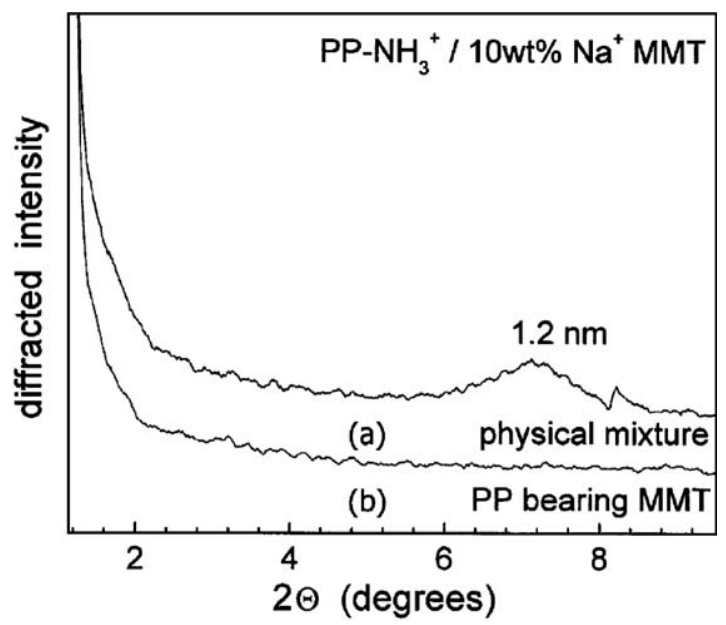

Fig. 15. X-ray diffraction patterns of PP-t- $\mathrm{NH}_{3}^{+} \mathrm{Cl}^{-} / \mathrm{Na}^{+}-\mathrm{MMT}(90 / 10$ weight ratio): (a) physical mixture by simple powder mixing at ambient temperature and (b) the same mixture after static melt-intercalation. Reprinted with permission from [33], Z. M. Wang et al., Macromolecules 36, 8919 (2003). (C) 2003, American Chemical Society. (at $170{ }^{\circ} \mathrm{C}$ and 10 metric ton for $15 \mathrm{~min}$ ) ATBN-MMT showed a $d$-spacing of $13.8 \AA$, indicating that a stable hybrid was formed. The small increase in the $d$-spacing is consistent with an intercalated structure, $c f$. a horizontal packing of polymer molecules in a monomer-bilayer film within the silicate gallery, much like the shorter

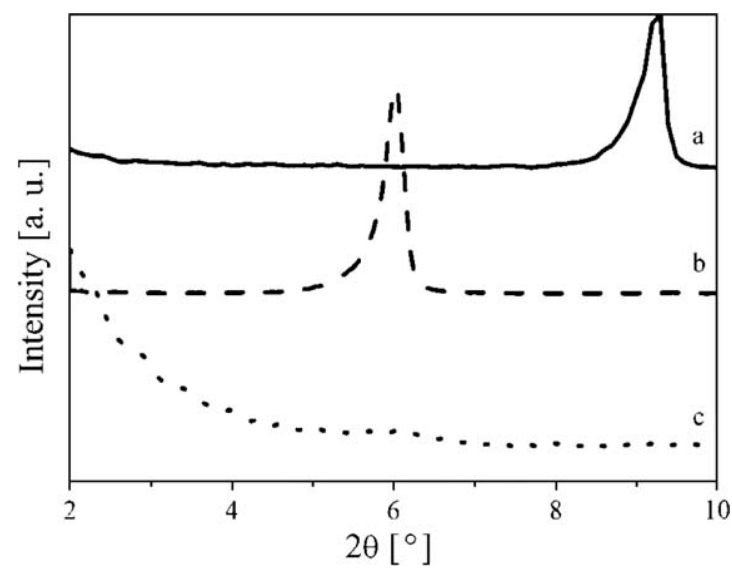

Fig. 16. WAXS traces of (a) neat PS (Mn: 106000), (b) 2-phenylethylammonium modified silicate and (c) ammonium-terminated polystyrene modified silicate. Reprinted with permission from [40], B. Hoffmann et al., Macromol. Rapid Commun. 21, 57 (2000). () 2000, John Wiley \& Sons. 
Table II. Synthetic conditions for ATBN modified silicates and resulting $d$-spacing.

\begin{tabular}{|c|c|c|c|c|c|c|c|}
\hline \multirow[b]{2}{*}{ No } & \multicolumn{2}{|c|}{ ATBN } & \multirow{2}{*}{$\begin{array}{l}\mathrm{HCl} \\
\mathrm{Mmol}\end{array}$} & \multicolumn{2}{|c|}{ MMT } & \multirow{2}{*}{$\begin{array}{c}\frac{d \text {-spacing }}{\mathrm{nm}} \\
\end{array}$} & \multirow[b]{2}{*}{ Refs } \\
\hline & $\mathrm{Mn}$ & mmol & & $\begin{array}{c}\text { CEC } \\
(\mathrm{meq} / 100 \mathrm{~g})\end{array}$ & $\mathrm{mmol}$ & & \\
\hline 1 & 1090 & 7.34 & 3.78 & 114.8 & 4.41 & 1.41 & [45] \\
\hline 2 & 1090 & 55.0 & 32.0 & 90.0 & 27.0 & 1.52 & [46] \\
\hline 3 & 3400 & 2.71 & 5.40 & 119 & 5.00 & $>8$ & [48] \\
\hline
\end{tabular}

alkyl-ammonium surfactants. ${ }^{80}$ For similar ATBN polymers however, researchers at Toyota found no peak in their XRD measurement of ATBN-MMT. ${ }^{48}$ In order to understand these two contrasting results, one must consider the different experimental conditions that were used in the two studies, given in Table II; the main difference is the ratio of ATBN ( $\mathrm{Mn}=1090 \mathrm{~g} / \mathrm{mol})$ to $\mathrm{HCl}$. In Refs. [45 and 46], a mixture of monovalent and neutral $\alpha, \omega$ diamine butadiene acrylonitrile was formed, while in Ref. [48], due to the excess of hydrochloric acid the vast majority of the amine end-groups of the ATBN $(\mathrm{Mn}=3400 \mathrm{~g} / \mathrm{mol})$ are charged. Thus, despite the fact that the silicates used have similar CEC; a much larger $d$-spacing is observed where both of the amines have been converted to ammonium ions.

Polymeric surfactants based on the copolymerization with VBC usually result in a very large increase in the $d$-spacing. For example, the polymerically modified clay based on a copolymer of styrene with vinylbenzyl chloride, in which benzyl chloride is further quaternized by an amine, had a $d$-spacing of $8 \mathrm{~nm}$. When styrene was changed to MMA, the resulting polymerically modified clay had a $d$-spacing of $6.7 \mathrm{~nm} .{ }^{91}$ It is very interesting that the work on a terpolymer, ${ }^{49}$ St-MMA-VBC, modified clay has been done by two research groups and the XRD results are significantly different. The work done by Akelah used the polymerization of St, MA and VBC, and this terpolymer was used to quaternize either tributylphosphine or triphenylphosphine; these two modified montmorillonites gave a $d$-spacing of about $15 \AA$, quantified by the XRD patterns. However, Zheng et al. ${ }^{64}$ reported a larger value, $49 \AA$ with a similar terpolymer surfactant. In this latter case, the starting material was vinylbenzyltrimethylammonium chloride, along with styrene and methyl methacrylate, and hectorite was used as the clay rather than montmorillonite. Since the ratio of starting materials, molecular weight and yield were either different or not available, it is not possible to directly compare the work of these investigators. It would be worthwhile to revisit these systems in a systematic manner, so as to see how these variables affect the $d$-spacing. Finally, for another three-component polymeric surfactant system, which includes St, LA, and VBC, there was reported a limitation on the extent of gallery expansion that could be achieved for a polymerically modified clay. By varying the amount of VBC in the system, three modified clays with different inorganic clay contents were obtained and the $d$-spacings are constant at about $4 \mathrm{~nm}$ in all systems, indicating an intercalated structure that is insensitive to the polymers' stoichiometry.

\section{PREPARATION AND MORPHOLOGY OF POLYMER CLAY NANOCOMPOSITES}

In common practice, when preparing polymer clay nanocomposites by melt compounding the clays must be rendered organophilic so as to become miscible with the polymeric matrix. Organophilicity, most often achieved through cation exchange by quaternary ammonium surfactants, raises serious concerns due to the ammonium surfactants' thermal stability; whose degradation occur by the Hofmann elimination reactions ${ }^{92}$ with an onset temperature of $150-200{ }^{\circ} \mathrm{C},{ }^{93}$ limiting substantially the
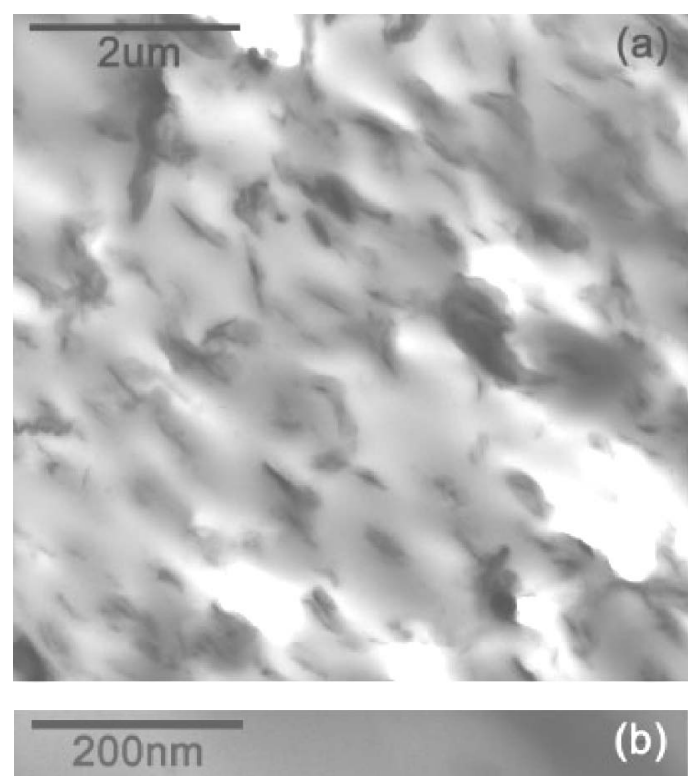

(b)

Fig. 17. TEM micrographs of PET/lauryl clay, low magnification (a) and higher magnification (b). Reprinted with permission from [96], M. C. Costache et al., Polym. Advan. Technol. 17, 764 (2006). (C) 2006, John Wiley \& Sons. 


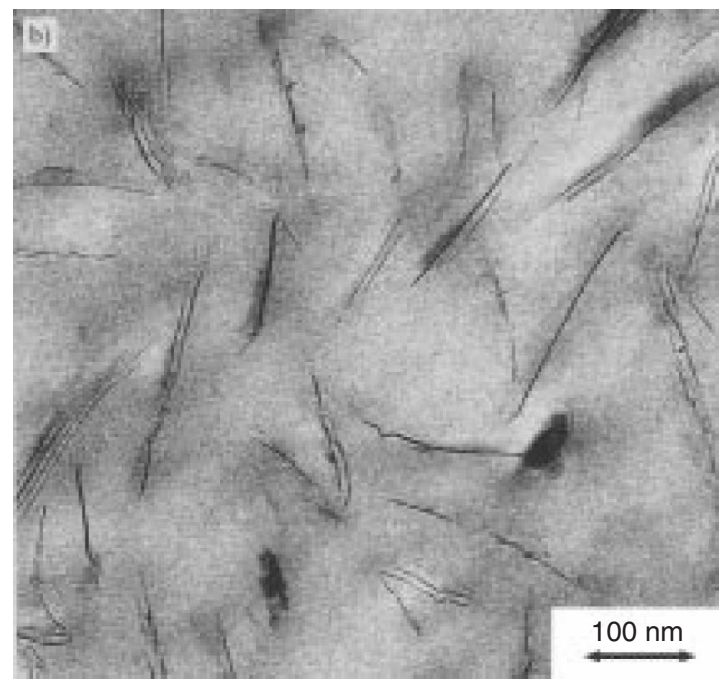

Fig. 18. TEM micrographs of the melt compound of PS with PS-t-NH $\mathrm{H}_{3}^{+}$/ silicate (silicate loading: $5 \mathrm{wt} \%$ ). Reprinted with permission from [40], B. Hoffmann et al., Macromol. Rapid Commun. 21, 57 (2000). (C) 2000, John Wiley \& Sons.

range of melt processing temperatures, especially for high melting point semi-crystalline polymers. ${ }^{94}$ For example, Yoon et al. $^{95}$ compounded PS with di-methyl-benzyl hydrogenated tallow ammonium chloride modified MMT (MMT-2MBHTA) at $210{ }^{\circ} \mathrm{C}$. Due to the limitation of thermal instability of the organo-clay, the interlayer spacing initially expanded to $3.5 \mathrm{~nm}$ but then decreased to $1.9 \mathrm{~nm}$ as the compounding time was increased. This effect was attributed to the thermal degradation of the clay's organic modification..$^{95}$

For strictly apolar polymers, such as PE and PP, functionalized polymers (like PE-g-MAH or PP-g-MAH) are required if one is to obtain thermodynamically stable nanoscale-dispersion of commercial alkyl-ammonium organoclays under melt intercalation conditions. Employing polyolefin based organic modifications for the clays can promote nanocomposite formation with matrices similar to the polymeric modification of the clays, without a need to add further functional groups to the matrix polymers. ${ }^{33}$ From a different viewpoint, polymerically modified clays can also be designed to possess higher thermal stability than alkyl-ammoniums, and thus can be used for nanocomposite melt processing at much higher temperatures than the commercially available organo-clays. One such example is the use of an oligomerically modified clay to form a PET-clay nanocomposite via melt processing. ${ }^{96}$ The processing temperature of PET is about $280^{\circ} \mathrm{C}$, which is well above the decomposition temperature of the common ammonium surfactants used in commercial organoclays. Nanocomposite hybrids from PET and lauryl-clay (clay was modified with an oligomeric surfactant containing lauryl acrylate and vinylbenzyl chloride) showed well dispersed filler in the PET matrix, as can be seen from the TEM images shown in Figure 17.

Generally, the intercalated or exfoliated structures of the polymerically modified clays are maintained when these clays are further blended with a polymer of the same chemistry, and in absence of strong polymer/clay interactions. For example, the family of VBC-based polymermodified clays has been successfully melt blended with PE, PP, PS, HIPS, ABS, SAN, PMMA, PET, depending on the comonomers of the VBC copolymers. Other such examples include PP-t- $\mathrm{NH}_{3}^{+} / \mathrm{MMT}$ mixed with PP by static melt intercalation process ${ }^{33}$ and PS-t- $\mathrm{NH}_{3}^{+}$/fluromica mixed with PS by melt compounding. ${ }^{40}$ Figure 18 shows such an exfoliated nanocomposite for PS mixed with PS-t- $\mathrm{NH}_{3}^{+} /$fluromica at $5 \%$ silicate loading.
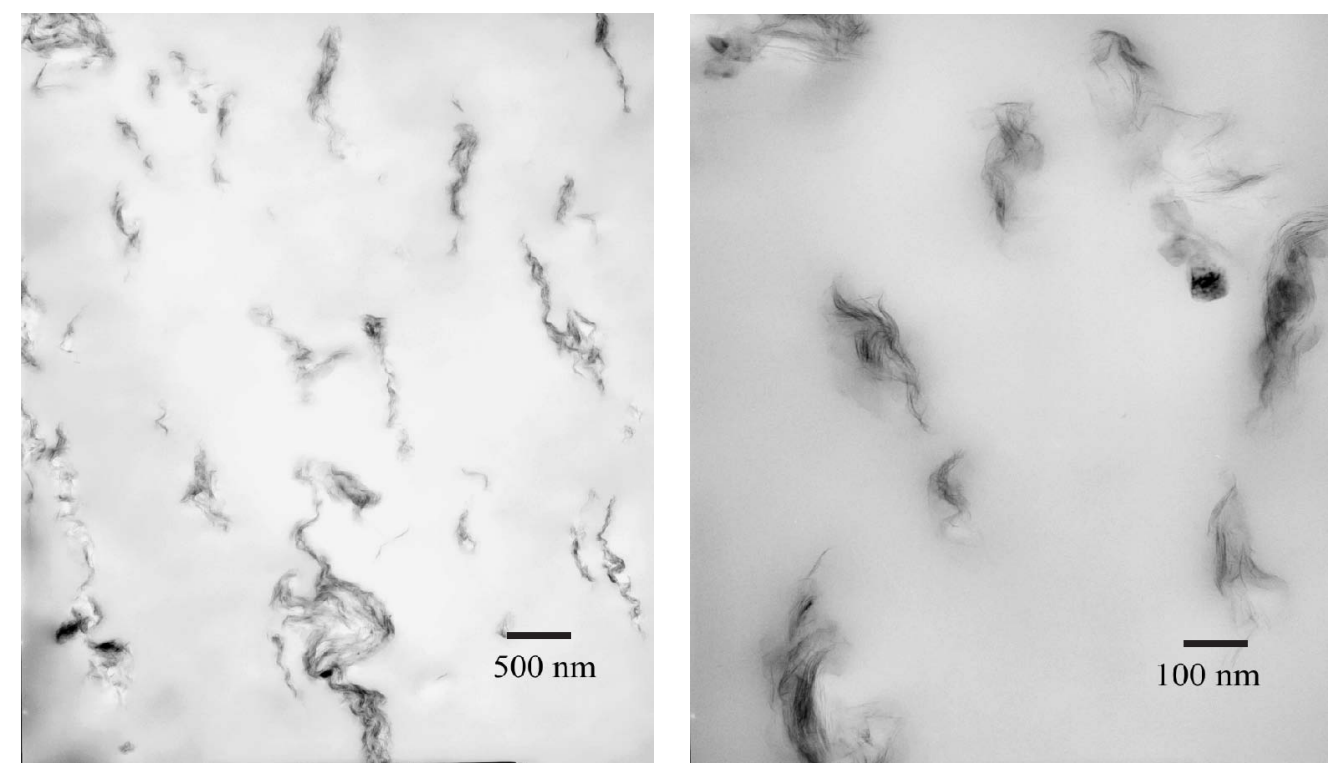

Fig. 19. TEM images of PP/clay nanocomposite based on triclay at $5 \%$ inorganic clay loading. Reprinted with permission from [58], J. Zhang et al., Polym. Degrad. Stab. 91, 641 (2006). (C) 2006, Elsevier. 


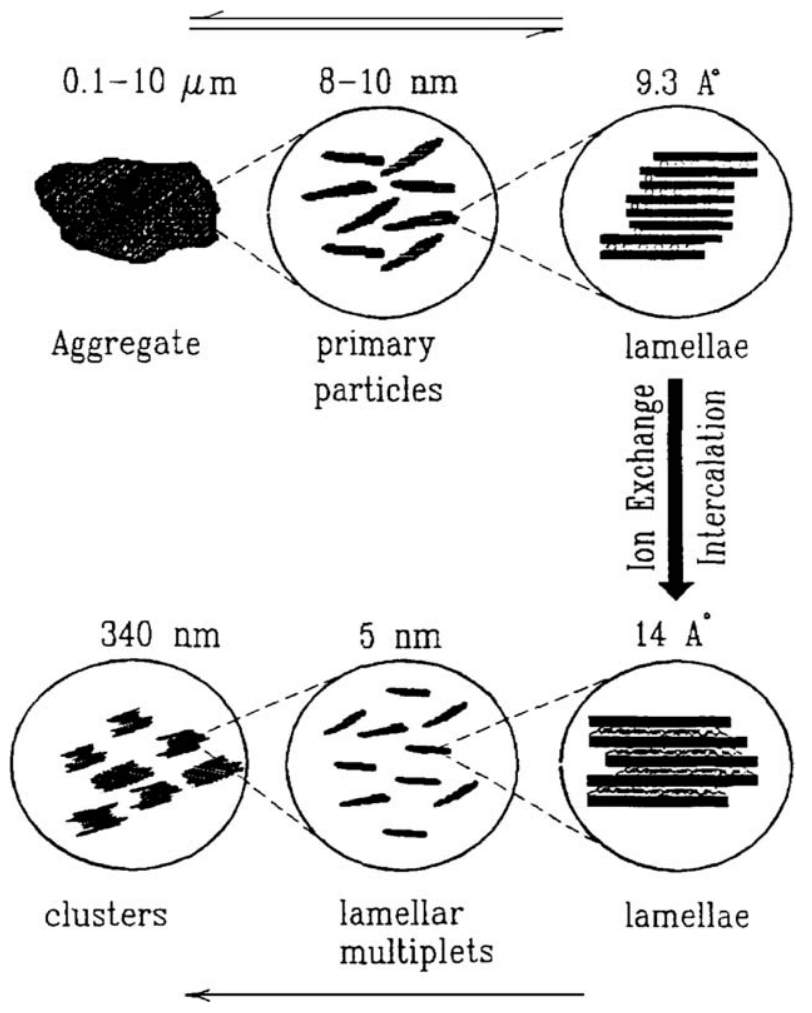

Fig. 20. Hierarchical model for MMT and ATBN-MMT nanocomposites. Reprinted with permission from [45], A. Akelah et al., Nanostruct. Mater. 4, 965 (1994). (C) 1994, Elsevier.

Beyer ${ }^{41}$ et al. probed the phase behavior of polystyrene with polystyrene modified clays, using five different molecular weight polystyrene surfactants ranging from 1700 to $17,000 \mathrm{~g} / \mathrm{mol}$. SAXS data reveal that the $d$-spacing of clay after each modification is fairly large and it depends on the molecular weight of the surfactant, in another words, the chain length of the surfactant. There was essentially no change in the SAXS data between the modified clay and the corresponding polystyrene hybrid. Similar behavior was found by Sepehr, ${ }^{97}$ where COPS clay was mixed with polystyrene, yielding either no change in the $d_{001}$-spacing or a reduction in $d_{001}$ in the nanocomposites compared to the one of the polymerically modified clay. These observations led the authors to conclude that phase-separated morphologies were formed.

In the PP-t-NH $H_{3}^{+} / \mathrm{MMT} / \mathrm{PP}$ nanocomposites prepared through static melt intercalation (no shear mixing applied), an exfoliated structure developed and was maintained after further diltution/mixing with unfunctionalized PP, as long as static melt conditions were maintained. That behavior was attributed to the terminal $\mathrm{NH}_{3}^{+}$functional group that seem to anchor the end-functionalized PP chains on the inorganic surfaces, and promote an exfoliated structure which can be maintained even after further mixing with neat $\mathrm{PP}^{33}$ Application of shear however, as for example when mixing the PP-t- $\mathrm{NH}_{3}^{+} / \mathrm{MMT}$ with neat $\mathrm{PP}$ in an extruder or a kneader, can lead the same systems to a mostly-intercalated nanocomposite structure. This behavior is strongly reminiscent of what happens when polyamide- 6 grafted montmorillonites - such as the Toyota polyamide- 6 hybrids ${ }^{2}$-or $\operatorname{poly}(\varepsilon$-caprolactone $)$ grafted clays $^{98}$ are co-extruded with the neat respective polymer, i.e., polyamide- 6 or PCL. In both these case the exfoliated structures of the polymer-bearing clays collapses upon mixing with the neat polymer matrix, a behavior which clearly originates from the strong hydrogenbonding interactions between those polymers and the silicates. ${ }^{99}$

In contrast to these systems, VBC-based polymermodified clays have been used in nanocomposites and in most cases, there is no change in the $d$-spacing of the polymer-modified clay and the nanocomposites resulting

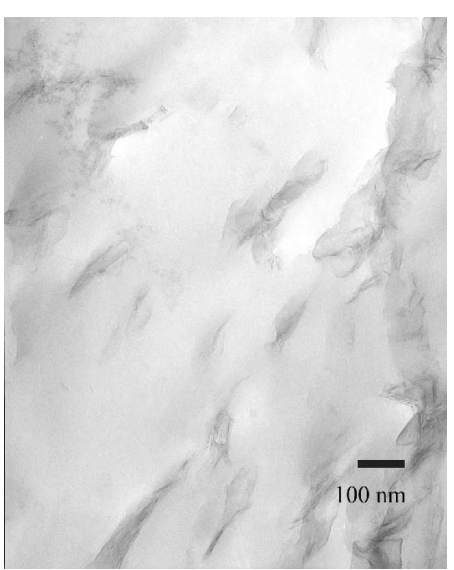

(a)

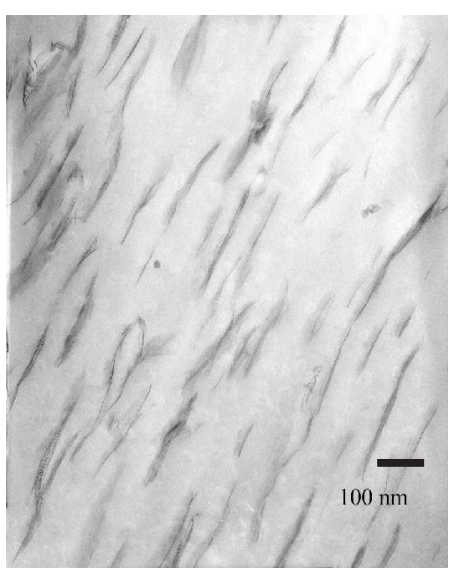

(b)

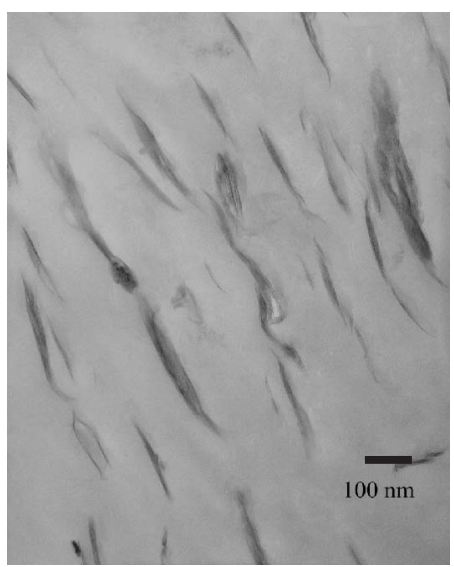

(c)

Fig. 21. TEM images of SAN/triclay nanocomposites at 5\% inorganic clay loading: (a) SAN/triclay nanocomposite. Reprinted with permission from [59], J. Zhang et al., Polym. Degrad. Stab. 91, 358 (2006). () 2006, Elsevier; (b) SAN/triclay II nanocomposite. Reprinted with permission from [57], J. Zhang et al., Polym. Adv. Technol. 16, 800 (2005). () 2005, John Wiley \& Sons; (c) SAN/triclay III nanocomposite. Reprinted with permission from [61], J. Zhang et al., Polym. Degrad. Stab. 91, 2665 (2006). (C) 2006, Elsevier. The inorganic clay content in triclay, triclay II and triclay III are $25 \%, 37.5 \%$, and $50 \%$. 


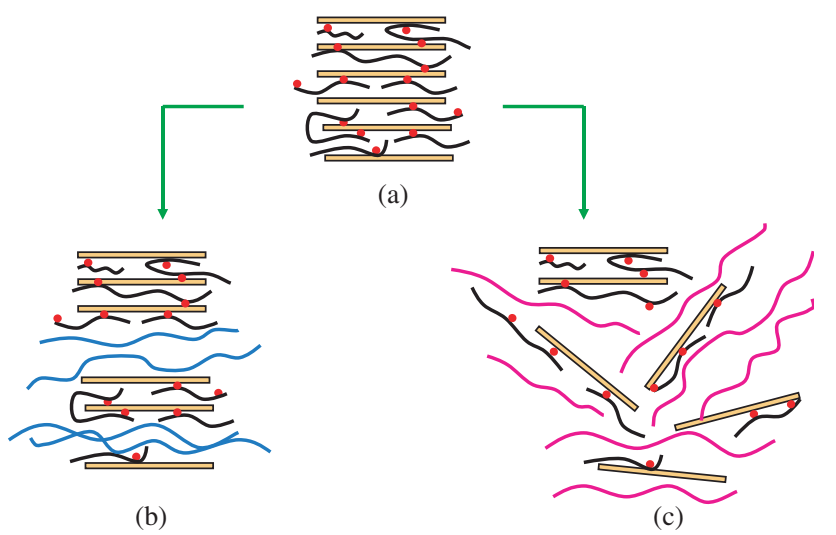

Fig. 22. Melt intercalation and exfoliation of polymerically modified clay: (a) Polymerically modified clay. Red dots stand for cations while black lines stand for polymeric surfactant. (b) Melt blend with non-polar polymer. Blue lines stand for non-polar polymer chains. Polymer chains intercalate into non-bridged clay platelets. (c) Melt blend with polar polymer. The rearrangement of the polycations leads to the exfoliation of clay palettes.

from further dilution in the respective neat polymer. For example, PE and PP nanocomposites based on triclay, ${ }^{58}$ in which clay is modified by a copolymer of VBC, St, and lauryl acrylate, showed good nanometer-dispersions, as seen by the TEMs in Figure 19. Two possible explanations were proposed: (a) the layers are already sufficiently expanded by the acrylate polymer to enable intercalation of the polyolefin without necessitating further expansion of the gallery spacing; (b) the dilution of the polymerically modified clay in the polyolefin leads to a decrease of the clay clusters' size, due to shear and/or thermodynamics. A hierarchical model, ${ }^{45}$ Figure 20, for montmorillonite and ATBN-MMT nanocomposites may be useful to describe the morphology evolution of polymerically-modified clay dispersed in these polymer matrices.

For the nanocomposites based on SAN polar polymer used to dilute a polymerically modified clay, the XRD patterns are significantly different compared with that of the polymerically modified clay. The strong reflections in the XRD for the polymerically modified clays are either broadened or disappear. Taking SAN/triclay system as an example, the TEM shows that the SAN/triclay exhibits an exfoliated structure, as shown in Figure 21, with increasing inorganic clay content in triclay, in which the clay platelets have a high possibility to be bridged.

Since there are generally extra cations available in the polymeric surfactant after the cation exchange process, it is quite possible that the polycations rearrange during the melt blending process, as shown in Figure 22, so that exfoliation of the clay can take place when clay, polymeric surfactant and polymer matrix interact with each other.

\section{NANOCOMPOSITE PROPERTIES}

Polymer clay nanocomposites exhibit significant improvements in mechanical and other properties at relatively low filler loadings (usually less than $10 \mathrm{wt} \%$ ) compared to conventional polymer composites containing a similar amount of macroscopic filler. Polymer layered silicate nanocomposite formation can concurrently increase the modulus, strength, heat resistance, barrier performance, and flame retardancy. Frequently used clays in polymer nanocomposite formation are organically modified clays, containing quaternary ammonium salts, typically containing about $30 \%$ organic and $70 \%$ silicate. Polymerically modified clays however usually contains about $70 \%$ polymeric "surfactant" and 30\% silicate, thus a significant amount of polymeric surfactant must be introduced in order to obtain the desired inorganic content, which may impact many aspects in the final nanocomposite.

\subsection{Mechanical Properties}

Kojima $^{100}$ reported a dramatic improvement in the mechanical properties of exfoliated polyamide 6 clay nanocomposites, even at low clay loading. For polymers, such as polystyrene, polyethylene, and polypropylene, significant improvements in tensile properties, such as tensile strength and modulus, are observed for nanocomposites based on organically modified clay. For nanocomposites based on polymerically modified clay, mechanical evaluation has been more limited and generally does not show dramatic improvements in the tensile properties. Taking PS/COPS nanocomposites as an example, there was a decrease of tensile strength for nanocomposites compared to virgin PS. ${ }^{51}$ For the triclay system, the tensile strength and modulus of the nanocomposites increase to a value higher than that in the virgin polymer by gradually increasing the alumino-silicate content in the polymerically modified clay. The elongation at break of polymerically modified clays shows different behavior than that seen for the common organically modified clays, which usually show reduced maximum elongation even at low clay loading. For PP/triclay nanocomposite at 1, 3, and $5 \%$ inorganic clay loading, the change of the elongation is small, from $580 \%$ in the virgin PP to $551 \%, 446 \%$, and $492 \%$ respectively. For PE/triclay, the decrease in elongation is larger; virgin PE shows $402 \%$ elongation while a $5 \%$ clay containing nanocomposite gives $185 \%$.

\subsection{Thermal Stabilities}

Thermogravimetric analysis can quantify thermal stability via characteristic temperatures that correspond to a certain level of weight loss; specifically, the onset temperature, which is commonly evaluated as the temperature at which $10 \%$ mass loss occurs, $T_{0.1}$, and the mid-point of degradation, $T_{0.5}$, are two such points. The enhancements seen for the polymerically modified clays and their respective nanocomposites are similar to those based on surfactant organo-clays. For a PS nanocomposite containing 25\% COPS clay (5\% silicate), the $T_{0.1}$ increases 
from $370{ }^{\circ} \mathrm{C}$ in PS to $387{ }^{\circ} \mathrm{C}$ and $T_{0.5}$ increase from $415{ }^{\circ} \mathrm{C}$ to $438{ }^{\circ} \mathrm{C}$ (in $\mathrm{N}_{2}$ ). These increases are slightly smaller than those of exfoliated PS nanocomposites based on VB16 organically-modified clay $^{101}$ in which clay is treated with $N, N$-Dimethyl- $n$-hexadecyl-(4-vinylbenzyl) ammonium chloride; this difference can be attributed to the different composite morphologies, since exfoliated nanocomposites generally show better enhancement than intercalated nanocomposites. The enhancement in thermal stability for PP and PE is comparable to those nanocomposites based on organically modified (surfactant) clays.

\subsection{Fire Properties}

Polymer nanocomposites based on layered silicate show significantly decreased flammability compared to the
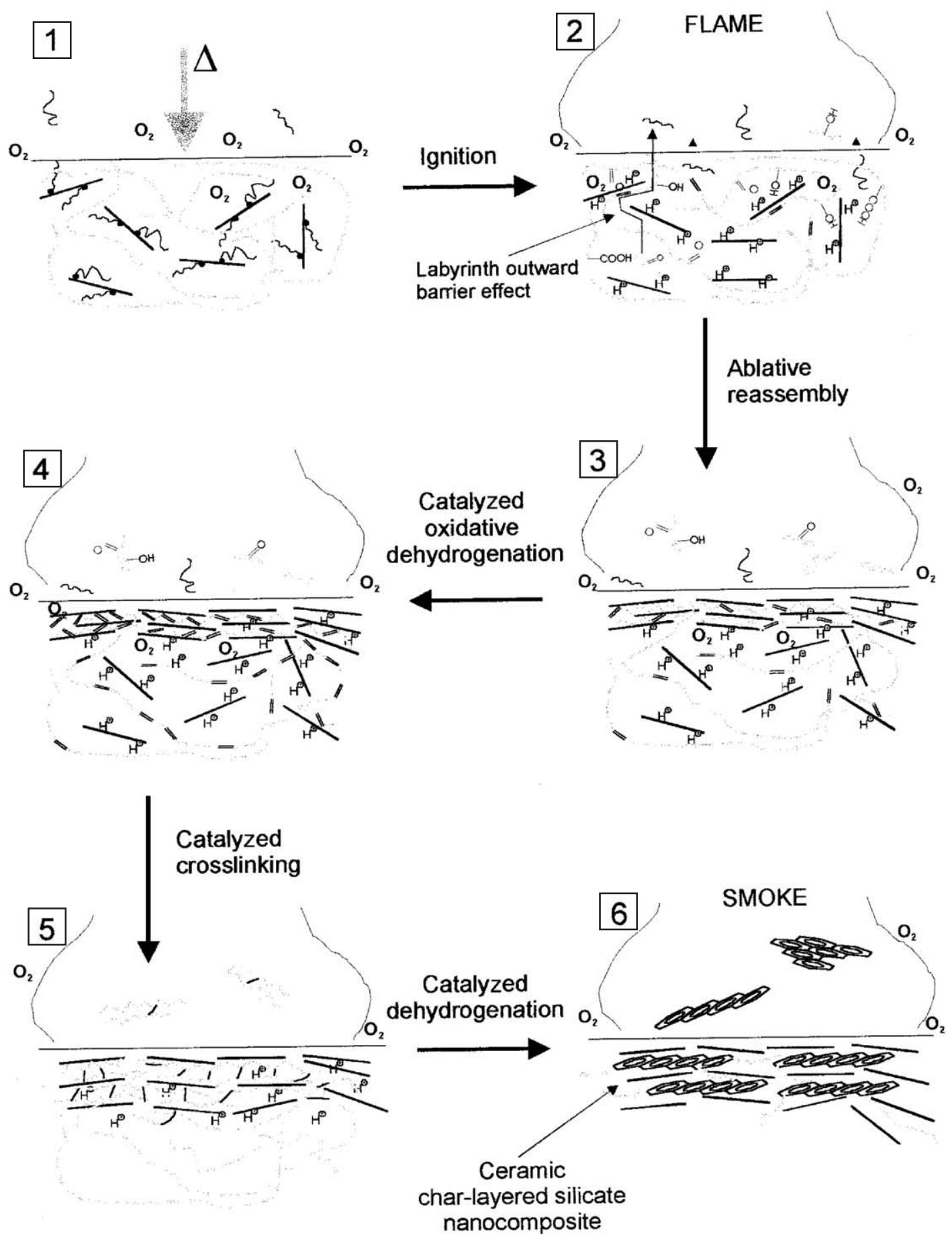

Fig. 23. Schematic representation of combustion mechanism and ablative reassembly of a nanocomposite during cone calorimeter experiments. Reprinted with permission from [105], M. Zanetti et al., Chem. Mater. 14, 881 (2002). (c) 2003, American Chemical Society. 
virgin polymer; this is usually evaluated by cone calorimetry. The single most important parameter quantified by a cone calorimetric measurement is the peak heat release rate (PHRR). Since generally a microcomposite does not give a reduced peak heat release rate while a nanocomposite does, cone calorimetry may also give information on the morphology of the system. ${ }^{102-104}$ The flame retardant mechanism for EVA clay nanocomposites has been proposed by Zanetti ${ }^{105}$ and is illustrated in Figure 23 . Heat transfer from an external source or from the flame promotes thermal decomposition of the organo-clay and degradation of the polymer (steps 1 and 2). This results in the creation of protonic catalytic sites on the clay layers that reassemble those on the surface of the burning material (step 3). The polyene obtained from EVA deacetylation can participate in two competitive reactions: peroxidation and chain scission to volatile partially-oxidized fragments and catalyzed dehydrogenation and oxidative dehydrogenation (step 4). The resulting conjugated polyene undergoes cross-linking and catalyzed dehydrogenation to form a charred surface layer (step 5), which combines and intercalates with the reassembling silicate layers to provide a sort of ceramic char-layered silicate nanocomposite (step 6).

For every polymer, there is a maximum reduction in PHRR which can be achieved. The reduction in the PHRR
Table III. PHRR reduction of PCN-P at 5\% silicate loading comparing with virgin (unfilled) polymer.

\begin{tabular}{|c|c|c|c|c|c|c|c|}
\hline \multirow{2}{*}{$\begin{array}{l}\text { Polymerically } \\
\text { modified clay }\end{array}$} & \multicolumn{7}{|c|}{ PHRR reduction compared to unfilled polymer (\%) } \\
\hline & PS & HIPS & ABS & SAN & PMMA & $\mathrm{PE}$ & PP \\
\hline COPS clay & 57 & 43 & 25 & - & 15 & 30 & 35 \\
\hline MAPS clay & 43 & 54 & 37 & - & 21 & 42 & 38 \\
\hline Lauryl clay & - & - & - & - & - & 44 & 40 \\
\hline Triclay & 61 & 51 & 35 & 42 & - & 60 & 57 \\
\hline Triclay II & 51 & 49 & 23 & 40 & - & 45 & 40 \\
\hline Triclay III & 32 & 35 & 23 & 38 & - & - & - \\
\hline
\end{tabular}

for the polymerically-modified clays frequently shows a value which is close to this maximum, which, if one believes that cone calorimetry can give information about morphology, means that the clay is as well-dispersed in the polymer as possible. At 5\% silicate loading, PS/COPS clay nanocomposite achieved a 57\% reduction in PHRR, while $\mathrm{PE} /$ triclay achieved a $60 \%$ reduction. Table III provides some examples of the reductions of PHRR for nanocomposites based on polymerically modified clays at $5 \%$ inorganic clay loading; the cone calorimetry was performed at $35 \mathrm{~kW} / \mathrm{m}^{2}$.

For the styrenic systems, triclay nanocomposites show the best reduction in PHRR. Since all the polymer nanocomposites were fabricated in the same way, the only<smiles>[R]c1ccc(C=C)cc1</smiles><smiles>C=Cc1ccccc1</smiles><smiles>C=Cc1ccc(CCl)cc1</smiles><smiles>[R]c1ccc(C(C)(C)C(c2ccc(C(c3ccc(CCl)cc3)C(C)(C)C)cc2)C(C)(C)C)cc1</smiles><smiles>[R]c1ccc(C(CC(C)C)C(C)(C)C)c(C(CC(C)C)c2ccc(CC(C)(C)C)cc2)c1</smiles>

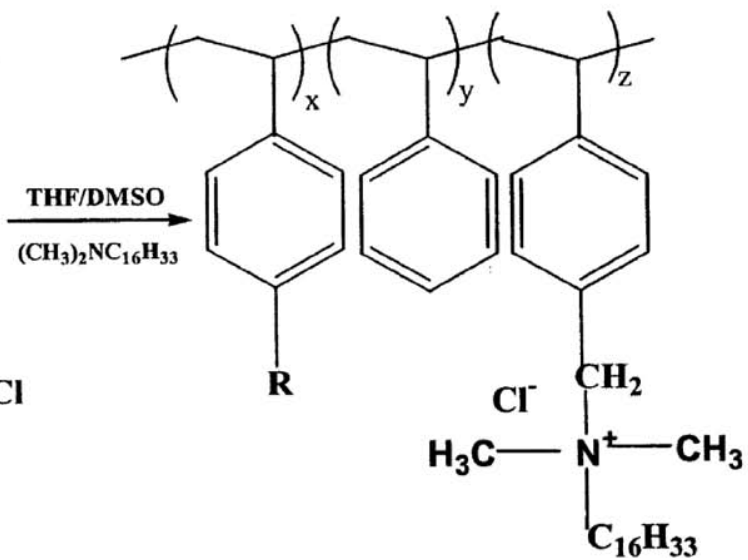

Fig. 24. Synthetic route for the formation of the terpolymer and its ammonium salt, $\mathrm{R}=$ phosphate moiety. Reprinted with permission from [56], X. Zheng and C. A. Wilkie, Polym. Degrad. Stab. 81, 539 (2003). (c) 2006, Elsevier. 


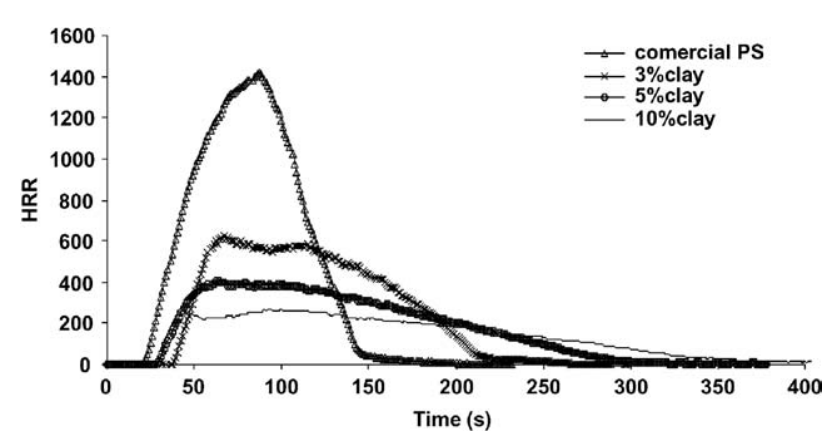

Fig. 25. Heat release curves for melt blended polystyrene nanocomposites, prepared using the $75 \%$ DPVPP modified clay. Reprinted with permission from [56], X. Zheng and C. A. Wilkie, Polym. Degrad. Stab. 81, 539 (2003). (C) 2006, Elsevier.

difference is the "surfactant" used for clay modification. Specifically, triclay is a copolymer of styrene, lauryl acrylate and vinylbenzyl chloride (VBC) and the inorganic content of the three triclays increases from $25 \%$ in triclay to $37.5 \%$ in triclay II to $50 \%$ in triclay III. For COPS clay, the surfactant is a copolymer of styrene and VBC, while in lauryl clay, the surfactant is a copolymer of lauryl acrylate and VBC. From these data, it seems that styrene and lauryl acrylate units alone are not as effective as their combination. The long alkyl chain on the lauryl acrylate may affect the nanocomposite formation in two ways: (1) increasing the miscibility with non-polar polymers and (2) lubrication from the alkyl chain. The presence of styrene units will promote char formation in the presence of clay. ${ }^{106}$

The tensile strength and modulus of the triclay nanocomposites increase with inorganic content, but the respective PHRR reductions are significantly reduced for non-polar polymer nanocomposites, which may indicate poorer nano-dispersion as the inorganic content increases. Obviously, the possibility of bridging between clay platelets in triclay III is very high, since there is a large excess of cations present in the surfactant. It should be very difficult for the polymer to penetrate between clay layers which are held together by bridging polycations, which would result in poorer dispersions. For SAN, there is almost no difference in terms of PHRR reduction between the three triclays, which suggests equally good nano-dispersion, but there is a significant difference for the other styrenics polymers. The polarity of the polymeric matrix may play an important role in the nanocomposite formation during melt compounding, as shown in Figure 22, with highly expanded polymerically modified clays.

Incorporating a flame retardant component, such as a phosphate, into a polymeric "surfactant" before it is exchanged with clay is another effective way to achieve flame retardancy. Such a synthetic route is shown in Figure 24 . For this polymerically modified clay, at $3 \%$ inorganic clay loading there is a $55 \%$ reduction in the PHRR for polystyrene, and at 5\% inorganic clay loading the reduction in PHRR becomes $70 \%$. These reductions are larger than what is seen for the typical polystyrene nanocomposite and this must mean that the phosphate plays an important role in the process; the corresponding heat release rate curves are shown in Figure 25.

Other thermomechanical properties such as rheological properties, dynamic mechanical thermal analysis ${ }^{107}$ were also investigated, but only for a limited number of systems and will not be discussed here.

\section{CONCLUSIONS}

A variety of types of polymerically modified clays, including one-end terminated, $\alpha-\omega$ two-end terminated, and multiple-cation containing polymeric "surfactants" have been synthesized and used for the modification of layered silicates and clays. These polymerically modified nanofillers are usually highly expanded compared to the common organo-clays based on cationic surfactants such as alkyl ammoniums. The polymerically modified clays usually show outstanding thermal stability and may be directly melt compounded with various polymers, i.e., a compatibilizer or a masterbatch is not required even for polyolefin systems. Polymerically modified clay and polymer matrices are frequently immiscible, but with proper design of the polymerically modified clay and the processing conditions, the clay clusters can be significantly reduced in size and can become well-dispersed, and thus nanocomposite formation can still be achieved. In addition, polymeric "surfactants" as organic modifications for clay offer unparalleled opportunities to incorporate additional functionalities that target specific property improvements, beyond the dispersion of the fillers in the polymer matrix. For example, incorporating phosphate moieties in polymeric "surfactants" for clays can significantly reduce the flammability of the nanocomposite.

\section{ABBREVIATIONS}

$\begin{array}{ll}\text { AA: } & \text { Acrylamide; } \\ \text { CEC: } & \text { Cation Exchange Capacity; } \\ \text { DAMB: } & N, N \text {-Diacryloyl Metribuzin; } \\ \text { DMBA: } & \text { Dimethyl Benzylamine; } \\ \text { DMHDA: } & N, N \text {-Dimethylhexadecylamine; } \\ \text { DPVPP: } & \text { Diphenyl 4-Vinylphenyl Phosphate; } \\ \text { GPC: } & \text { Gel Permeation Chromatography; } \\ \text { IM: } & \text { Imidazol; } \\ \text { LA: } & \text { Lauryl Acrylate; } \\ \text { MAH: } & \text { Maleic Anhydride; } \\ \text { MHAB: } & \text { 2-Methyacryloyloxyethylhexadecyl } \\ & \text { dimethylammonium Bromide; } \\ \text { MMA: } & \text { Methyl Methacrylate; } \\ \text { MMT: } & \text { Montmorillonite; } \\ \text { Mn: } & \text { Number Average Molecular Weight; } \\ \text { Mw: } & \text { Weight Average Molecular Weight; }\end{array}$




$\begin{array}{ll}\text { NSt: } & \text { 4-Nonylstyrene; } \\ \text { PBd: } & \text { Polybutadiene; } \\ \text { SAXS: } & \text { Small-Angle X-ray Scattering; } \\ \text { St: } & \text { Styrene; } \\ \text { TEA: } & \text { Triethylamine; } \\ \text { TBP: } & \text { Tributylphosphine; } \\ \text { TMA: } & \text { Trimethylamine; } \\ \text { TPP: } & \text { Triphenylphosphine; } \\ \text { VBC: } & \text { Vinylbenzyl Chloride; } \\ \text { VBTACl: } & \text { (ar-)Vinylbenzyltrimethylammonium } \\ & \text { Chloride. }\end{array}$

\section{References and Notes}

1. (a) A. Blumstein, Bull. Soc. Chim. Fr. 899 (1961); (b) A. Blumstein, J. Polym. Sci. A 3, 2653 (1965); (c) A. Blumstein, J. Polym. Sci. A 3, 2665 (1965).

2. (a) A. Usuki, M. Kawasumi, Y. Kojima, A. Okada, T. Kurauchi, and O. Kamigaito, J. Mater. Res. 8, 1174 (1993); (b) A. Usuki, Y. Kojima, M. Kawasumi, A. Okada, Y. Fukushima, T. Kurauchi, and O. Amigaito, J. Mater. Res. 8, 1179 (1993); (c) Y. Kojima, A. Usuki, M. Kawasumi, A. Okada, Y. Fukushima, T. Kurauchi, and O. Kamigaito, J. Mater. Res. 8, 1185 (1993).

3. M. Alexandre and P. Dubois, Mater. Sci. Eng. 28, 1 (2000).

4. E. P. Giannelis, R. Krishnamoorti, and E. Manias, Adv. Polym. Sci. 138, 107 (1999).

5. M. Biswas and S. Sinha Ray, Adv. Polym. Sci. 155, 167 (2001).

6. S. Sinha Ray and M. Okamoto, Prog. Polym. Sci. 28, 1539 (2003).

7. A. Usuki, N. Hasegawa, and M. Kato, Adv. Polym. Sci. 179, 135 (2005).

8. T. J. Pinnavaia and G. W. Beall, Polymer-Clay Nanocomposites, Wiley, West Sussex (2000).

9. S. M. Auerbach, K. A. Carrado, and P. K. Dutta, Handbook of Layered Materials (2004).

10. K. E. Strawhecker and E. Manias, Chem. Mater. 12, 2943 (2000).

11. K. E. Strawhecker and E. Manias, Macromolecules 34, 8475 (2001).

12. J. Wu and M. Lerner, Chem. Mater. 5, 835 (1993).

13. K. E. Strawhecker and E. Manias, Chem. Mater. 15, 844 (2003).

14. R. A. Vaia, H. Ishii, and E. P. Giannelis, Chem. Mater. 5, 1694 (1993).

15. E. P. Giannels, Adv. Mater. 8, 29 (1996).

16. R. A. Vaia and E. P. Giannelis, Macromolecules 30, 7990 (1997).

17. R. A. Vaia and E. P. Giannelis, Macromolecules 30, 8000 (1997).

18. T. D. Fornes, P. J. Yoon, H. Keskkula, and D. R. Paul, Polymer 42, 9929 (2001).

19. T. D. Fornes and P. R. Paul, Macromolecules 37, 7698 (2004).

20. J. W. Gilman, T. Kashiwagi, E. P. Giannelis, E. Manias, S. Lomakin, J. D. Litchtenham, and P. Jones, Nanocomposites: Radiative gasification and vinyl polymer flammability, Fire Retardancy of Polymers: The Use of Intumescence, edited by M. Le Bras, G. Camino, S. Bourbigot, and R. Delobel, Royal Society of Chemistry, London (1998), Vol. 201.

21. J. W. Gilman, C. L. Jackson, A. B. Morgan, E. Manias, E. P. Giannelis, M. Wuthenow, D. Hilton, and S. H. Phillips, Chem. Mater. 12, 1866 (2000).

22. E. Manias, H. Chen, R. Krishnamoorti, J. Genzer, E. J. Kramer, and E. P. Giannelis, Macromolecules 33, 7955 (2000).

23. D. Wang, J. Zhu, Q. Yao, and C. A. Wilkie, Chem. Mater. 14, 3837 (2002).

24. J. Zhang and C. A. Wilkie, Polym. Degrad. Stab. 80, 163 (2003).

25. D. Wang and C. A. Wilkie, Polym. Degrad. Stab. 80, 171 (2003).

26. J. Zhang, P. K. Gupta, and C. A. Wilkie, Polymer 47, 4537 (2006).
27. E. Manias, A. Touny, L. Wu, K. Strawhecker, B. Lu, and T. C. Chung, Chem. Mater. 13, 3516 (2001).

28. M. Kawasumi, N. Hasegawa, M. Kato, A. Usuki, and A. Okada, Macromolecules 30, 6333 (1997).

29. C. Y. Lew, W. R. Mupphy, and G. M. MCNally, Polym. Eng. Sci. 44, 1027 (2004)

30. C. M. Koo, H. T. Ham, S. O. Kim, K. H. Wang, and I. J. Chung, Macromolecules 35, 5116 (2002).

31. W. Lertwimolnun and B. Vergnes, Polymer 46, 3462 (2005).

32. M. V. Burmistr, K. M. Sukhyy, V. V. Shilov, P. Pissi, A. Spanoudaki, I. Sukha, V. I. Tomilo, and Y. P. Gomza, Polymer 46, 12226 (2005).

33. Z. M. Wang, H. Nakajima, E. Manias, and T. C. Chung, Macromolecules 36, 8919 (2003).

34. B. Jang and C. A. Willkie, Macromolecules 38, 6533 (2005).

35. A. C. Balazs, C. Singh, and E. Zhulina, Macromolecules 31,8370 (1998).

36. S. W. Sides, B. J. Kim, E. J. Kramer, and G. H. Fredrickson, Phys. Rev. Lett. 96, 250601 (2006).

37. M. W. Weimer, H. Chen, E. P. Giannelis, and D. Y. Sogah, J. Am. Chem. Sco. 121, 1615 (1999).

38. X. Y. Huang and W. J. Brittain, Macromolecules 34, 3255 (2000).

39. K. S. Katti, D. Sikdar, D. R. Katti, P. Ghosh, and D. Verma, Polymer 47, 403 (2006).

40. B. Hoffmann, C. Dietrich, R. Thomann, C. Friedrich, and R. Mulhaupt, Macromol. Rapid Commun. 21, 57 (2000).

41. F. L. Beyer, N. C. B. Tan, A. Dasgupta, and M. E. Galvin, Chem. Mater. 14, 2983 (2002).

42. R. P. Quirk and Y. Lee, J. Polym. Sci. Part A: Polym. Chem. 38, 145 (2000).

43. J. Y. Dong, Z. M. Wang, H. Han, and T. C. Chung, Macromolecules 35,9352 (2002).

44. T. C. Chung, J. Organometal. Chem. 690, 6292 (2005).

45. A. Akelah, N. Salahuddin, A. Hilter, E. Baer, and A. Moet, Nanostruct. Mater. 4, 965 (1994).

46. A. Akelah, N. Salahuddin, A. Hilter, E. Baer, and A. Moet, Mater. Lett. 22, 97 (1995).

47. A. Okada, K. Fukumori, A. Usuki, Y. Y. Kojima, N. Sato, T. Kurauchi, and O. Kamigaito, Polym. Preprints 32, 540 (1991).

48. A. Usuki, T. Mizutani, Y. Fukushima, M. Fujimoto, K. Fukumori, Y. Kojima, N. Sato, T. Kurauchi, and O. Kamigaito, US Patent 4,889,885 (1989).

49. N. Salahuddin and H. Akelah, Polym. Adv. Technol. 13, 339 (2002).

50. A. Rehab, A. Akelah, and M. M. El-Gamal, J. Polym. Sci. A: Polym. Chem. 40, 2513 (2002).

51. S. Su, D. D. Jiang, and C. A. Wilkie, Polym. Degrad. Stab. 83, 333 (2004).

52. S. Su, D. D. Jiang, and C. A. Wilkie, Polym. Degrad. Stab. 83,321 (2004).

53. S. Su, D. D. Jiang, and C. A. Wilkie, Polym. Degrad. Stab. 84, 269 (2004).

54. J. Zhang and C. A. Wilkie, Thermochimica Acta 430, 107 (2005).

55. J. Zhang and C. A. Wilkie, Polymer 47, 5736 (2006).

56. X. Zheng and C. A. Wilkie, Polym. Degrad. Stab. 81, 539 (2003).

57. J. Zhang, D. D. Jiang, D. Wang, and C. A. Wilkie, Polym. Adv. Technol. 16, 800 (2005).

58. J. Zhang, D. D. Jiang, D. Wang, and C. A. Wilkie, Polym. Degrad. Stab. 91, 641 (2006).

59. J. Zhang, D. D. Jiang, and C. A. Wilkie, Polym. Degrad. Stab. 91, 358 (2006).

60. J. Zhang, D. D. Jiang, and C. A. Wilkie, Polym. Degrad. Stab. 91, 298 (2006).

61. J. Zhang, D. D. Jiang, D. Wang, and C. A. Wilkie, Polym. Degrad. Stab. 91, 2665 (2006).

62. X. Zheng, D. D. Jiang, D. Wang, and C. A. Wilkie, Polym. Degrad. Stab. 91, 289 (2006). 
63. X. Zheng, D. D. Jiang, and C. A. Wilkie, Thermochimica Acta 435, 202 (2005).

64. X. Zheng, D. D. Jiang, and C. A. Wilkie, Polym. Degrad. Stab. 91, 108 (2006).

65. S. Su, D. D. Jiang, and C. A. Wilkie, Polym. Degrad. Stab. 84,279 (2004).

66. S. Su, D. D. Jiang, and C. A. Wilkie, J. Vinyl Add. Technol. 10, 44 (2004).

67. K. Chrissopoulou, I. Altintzi, S. H. Anastasiadis, E. P. Giannelis, M. Pitsikalis, N. Hadjichristidis, and N. Theophilou, Polymer 46, 12440 (2005).

68. W. Xie, Z. Gao, W. P. Pan, R. Vaia, D. Hunter, and A. Singh, Polym. Mater. Sci. Eng. 83, 284 (2000).

69. J. Zhu, A. B. Morgan, F. J. Lamelas, and C. A. Wilkie, Chem. Mater. 13, 3774 (2001).

70. L. A. Utracki, Clay-Containing Polymeric Nanocomposites, 1st edn., Shawbury, Shrewsbury, Shropshire UK: RAPRA (2004).

71. A. Leszczynska, J. Njuguna, K. Pielichowski, and J. R. Banerjee, Thermochimica Acta 453, 75 (2007).

72. P. Scherrer, Nachr. Ges. Wiss. Gott 2, 96 (1918).

73. A. B. Morgan and J. W. Gilman, J. Appl. Polym. Sci. 87, 1329 (2003).

74. R. A. Vaia, W. D. Liu, and H. Koerner, J. Polym. Sci. Part B-Polym. Phys. 41, 3214 (2003).

75. M. Gunter, P. Reichert, R. Mülhaupt, and W. Gronski, Polym. Mater. Sci. Eng. 82, 228 (2000).

76. S. Bourbigot, D. L. Vanderhart, J. W. Gilman, W. H. Awad, R. D. Davis, A. B. Morgan, and C. A. Wilkie, J. Polym. Sci., Part B: Polymer Physics 41, 3188 (2003).

77. W. L. Ijdo, S. Kemnetz, and D. Benderly, Polym. Eng. Sci. 46, 1031 (2006).

78. (a) R. Wagener and T. J. G. Reisinger, Polymer 44, 7513 (2003); (b) J. Zhao, A. B. Morgan, and J. D. Harris, Polymer 46, 8641 (2005); (c) M. A. Treece and J. P. Oberhauser, Macromolecules 40, 571 (2007); (d) M. A. Treece and J. P. Oberhauser, Polymer 48, 1083 (2007).

79. A. Weiss, Angew. Chem. Internat. Edit. 2, 134 (1963).

80. E. Hackett, E. Manias, and E. P. Giannelis, J. Chem. Phys. 108, 7410 (1998).

81. G. Lagaly, Solid State Ionics 22, 43 (1986).

82. R. A. Vaia, R. K. Teukolsky, and E. P. Giannelis, Chem. Mater. 6, 1017 (1994).

83. V. Kuppa, S. Menakanit, R. Krishnamoorti, and E. Manias, J. Polym. Sci. B: Polym. Phys. 41, 3285 (2003).

84. V. Kuppa and E. Manias, J. Polym. Sci. B: Polym. Phys. 43, 3460 (2005).

85. V. Kuppa, T. M. D. Foley, and E. Manias, Europ. Phys. J. E 12, 159 (2003).
86. V. Kuppa and E. Manias, J. Chem. Phys. 118, 3421 (2003).

87. V. Kuppa and E. Manias, Chem. Mater. 14, 2171 (2002).

88. (a) E. Manias, V. Kuppa, D. B. Zax, and D.-K. Yang, Colloids Surf. A 187-188, 509 (2001); (b) E. Hackett, E. Manias, and E. P. Giannelis, Chem. Mater. 12, 2161 (2000); (c) M. C. Costache, D. Wang, M. J. Heidecker, E. Manias, and C. A. Wilkie, Polym. Adv. Technol. 17, 272 (2006).

89. G. J. Fleer, M. A. Cohen Stuart, J. M. H. M. Scheutjens, T. Cosgrove, and B. Vincent, Polymers at Interfaces, Springer (1993), and references therein.

90. S. Williams-Daryn and R. K. Thomas, J. Colloid Interface Sci. 255, 303 (2002).

91. S. Su, Ph.D. Dissertation, Marquette University (2004).

92. A. C. Cope and E. R. Trumbull, Org. React. 11, 317 (1960).

93. F. Kooli and P. C. M. M. Magusin, Clay Miner. 40, 233 (2005).

94. Z. M. Wang, T. C. Chung, J. W. Gilman, and E. Manias, J. Polym. Sci. B: Polym. Phys. 41, 3173 (2003).

95. J. T. Yoon, W. H. Jo, M. S. Lee, and M. B. Ko, Polymer 42, 329 (2001).

96. M. C. Costache, M. J. Heidecker, E. Manias, and C. A. Wilkie, Polym. Advan. Technol. 17, 764 (2006).

97. M. Sepehr, L. A. Utracki, X. Zheng, and C. A. Wilkie, Polymer 46, 11557 (2005).

98. (a) P. B. Messersmith and E. P. Giannelis, Chem. Mater. 5, 1064 (1993); (b) P. B. Messersmith and E. P. Giannelis, J. Polym. Sci. A Polym. Chem. 33, 1047 (1995).

99. R. Krishnamoorti and E. P. Giannelis, Langmuir 17, 1448 (2001).

100. Y. Kojima, A. Usuki, M. Kawasumi, A. Okada, Y. Fukushima, T. Kurauchi, and O. Kamigaito, J. Mater. Res. 8, 1185 (1993).

101. J. Zhu, A. B. Morgan, F. J. Lamelas, and C. A. Wilkie, Chem. Mater. 13, 3774 (2001).

102. J. W. Gilman, T. Kashiwagi, M. Nyden, J. E. T. Brown, C. L. Jackson, S. Lomakin, E. P. Giannelis, and E. Manias, Chemistry and Technology of Polymer Additives, edited by S. Al-Maliaka, A. Golovoy, and C. A. Wilkie, Blackwell Scientific, London (1998), Vol. 249.

103. M. Zanetti, G. Camino, D. Canavese, A. B. Morgan, F. J. Lamelas, and C. A. Wilkie, Chem. Mater. 14, 189 (2002).

104. J. Zhu, P. Start, K. A. Mauritz, and C. A. Wilkie, Polym. Degrad. Stab. 77, 253 (2002).

105. M. Zanetti, T. Kashiwagi, L. Falqui, and G. Camino, Chem. Mater. 14, 881 (2002).

106. T. Panagiotou and Y. Levendis, Combust. Flame 99, 53 (1994).

107. M. Sepehr, L. A. Utracki, X. Zheng, and C. A. Wilkie, Polymer 46, 11569 (2005).

108. A. Akelah, A. Rehab, E.-R. Kenawy, and M. A. Abou Zeid, J. Appl. Polym. Sci. 101, 1121 (2006).

Received: 27 April 2007. Accepted: 22 June 2007. 